\title{
Heteropolyacid-Based Materials as Heterogeneous Photocatalysts
}

\author{
Giuseppe Marcì, ${ }^{*[a]}$ Elisa I. García-López, ${ }^{[a]}$ and \\ Leonardo Palmisano $^{[a]}$
}

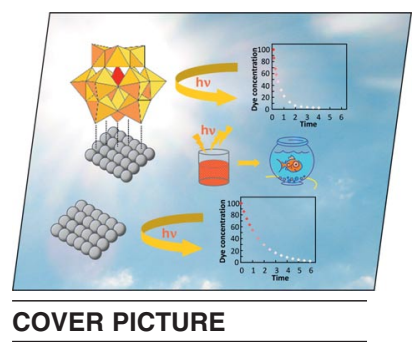

Keywords: Heterogeneous catalysis / Heteropolyacids / Photochemistry / Polyoxometalates

\begin{abstract}
Heteropolyacids (HPAs) that are often used as heteropolyanions are cheap and stable compounds that have been extensively used as acid and oxidation catalysts as a result of their strong Brønsted acidity and ability to undergo multielectron-transfer reactions. HPAs, which are very soluble in water and polar solvents, have been also used as homogeneous photocatalysts for the oxidation of organic substrates in the presence of oxygen, but their use in heterogeneous systems is by far desirable. Dispersing HPAs onto solid supports with high surface area is useful to increase their specific sur-
\end{abstract}

face area and hence (photo)catalytic activity. Moreover, owing to the high energy gap between the HOMO and LUMO positions of the HPAs, these compounds are activated only by UV light. Consequently, only less than $5 \%$ of the solar light can be used in photocatalytic reactions, which restricts the practical application of HPAs. This microreview is oriented to describe the reported literature on the use of HPAbased materials as heterogeneous photocatalysts for environmental purposes, that is, for the complete or partial oxidation or reduction of organic molecules.

\section{Introduction}

Heterogeneous photocatalysis is an unconventional technology that has received increasing interest over the last decades. Since Fujishima and Honda achieved UV-light-induced water cleavage by using a $\mathrm{TiO}_{2}$ photoanode, ${ }^{[1]}$ photocatalysis has attracted significant attention because of its promising applications, which are mainly focused on the degradation of organic and inorganic pollutants in both the vapor and liquid phases. ${ }^{[2-4]}$ This catalytic photoassisted technology is based on the use of a semiconductor that is irradiated with energy higher or equal to its band gap $\left(E_{\mathrm{g}}\right)$, which causes the formation of holes $\left(\mathrm{h}^{+}\right)$in the valence band and electrons $\left(\mathrm{e}^{-}\right)$in the conduction band. The photogenerated positive holes $\left(\mathrm{h}^{+}\right)$can directly react with a substrate to oxidize it or to form strongly oxidizing hydroxyl radicals $(\mathrm{OH})$ in the presence of water. Hydroxyl radicals and/or $\mathrm{h}^{+}$have been proposed as the oxidizing species, and they are responsible for unselective degradation of the organic substrates. Electrons are trapped by oxygen molecules that can subsequently react with water to form hydroxyl radicals also (Figure 1). Moreover, the electrons can directly reduce the substrate as showed in Figure 1.

[a] Dipartimento di Energia, Ingegneria dell'Informazione e Modelli Matematici, Università degli Studi di Palermo, Viale delle Scienze Ed. 6, 90128 Palermo, Italy E-mail: giuseppe.marci@unipa.it http://www.unipa.it/photocatalysis

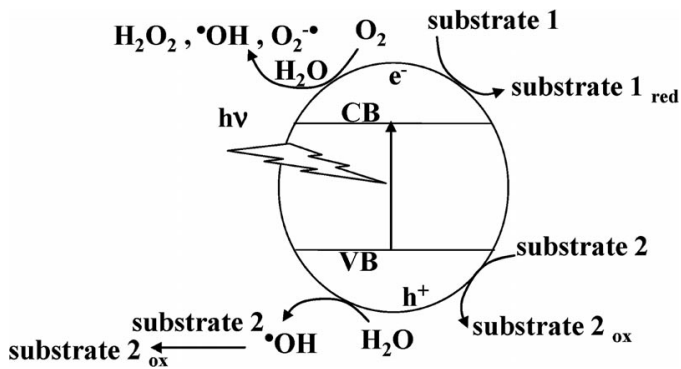

Figure 1. Mechanism of the photocatalytic reaction by using a semiconductor as a photocatalyst.

Recently, some efforts have been devoted to increasing the selectivity of $\mathrm{TiO}_{2}$-based photocatalytic processes for partial oxidation and synthetic purposes. ${ }^{[5]}$ The main advantage of photocatalysis consists in the mild experimental conditions under which the experiments can be carried out, that is, atmospheric pressure and room temperature. The whole process can be divided into five steps: absorption of light, separation of electron-hole pairs, adsorption of the reagents, redox reaction, desorption of the products. Semiconductor metal oxides are traditionally used as photocatalysts, although alternative solids have also been tested, but it is generally accepted that, until now, $\mathrm{TiO}_{2}$ is the most reliable material. It can be used under UV irradiation at wavelengths shorter than $385 \mathrm{~nm}$, which corresponds to its band gap. The use of $\mathrm{TiO}_{2}$ has evidenced several drawbacks, ${ }^{[6]}$ such as small amounts of photons absorbed in the visible region, high recombination rate for the photopro- 
duced electron-hole pairs, difficulty to improve its activity by loading or doping, and deactivation in the absence of water vapor, particularly in the gas-solid regime for the degradation of aromatics. ${ }^{[7]}$ Consequently, much effort has been devoted to modifying its physicochemical and electronic properties. The use of sensitizers on the $\mathrm{TiO}_{2}$ surface or coupling with other semiconductors and/or metal or non-metal species have evidenced modest improvements. ${ }^{[8]}$ At the same time, attempts have been addressed to develop alternative materials to $\mathrm{TiO}_{2}{ }^{[6]}$ as composites prepared by coupling two or more oxides to obtain mixed particles, but these photocatalysts have not been generally able to give rise to the total degradation of the pollutants both in the liquid-solid and gas-solid regimes.

Relatively little attention has been focused, instead, on the use of polyoxometalates (POMs) or polyoxometalatebased materials as heterogeneous photocatalysts. POMs are a wide class of discrete nanosized transition-metal-oxygen clusters. ${ }^{[9]}$ They exhibit interesting physicochemical properties that allow their use in analytical and materials chemistry, nanoscience, catalysis, magnetism, medicine, and photochemistry. ${ }^{[10]}$ The large number of structural types of POMs can be divided into three classes: heteropolyanions, isopolyanions, and Mo-blue and Mo-brown reduced POM centers. ${ }^{[1]}$ Notably, IPAs show significant and well-documented photocatalytic activity, ${ }^{[12]}$ although in this microreview we have confined ourselves to present only HPA-based materials. Dozens of types and stoichiometries of HPAs are known, including acids and their salts. However according to Pope and Muller it is convenient to classify them starting from the symmetrical "parent" polyanion; that is, Keggin, Wells-Dawson, Anderson-Evans, and Dexter-Silverton structures. ${ }^{[13]}$ We will only treat the first two classes, par- ticularly the Keggin structure, the first to be characterized and widely used in catalysis and photocatalysis. Both Keggin $\left\{\mathrm{XM}_{12} \mathrm{O}_{40}\right\}$ and Wells-Dawson $\left\{\mathrm{X}_{2} \mathrm{M}_{18} \mathrm{O}_{62}\right\}$ anions include heteroanions, in which a heteroatom $\mathrm{X}$ is present in $\mathrm{XO}_{4}{ }^{-}$as $\mathrm{PO}_{4}{ }^{3-}$ and $\mathrm{SiO}_{4}{ }^{3-}$, and the so-called addenda atom, commonly W or Mo. HPA tungstophosphates are the largest POM subclass. "Lacunary" structures, in contrast to "plenary" ones, result from the removal of one or more addenda atoms. The Keggin structure, for instance in the polyanion $\left[\mathrm{PW}_{12} \mathrm{O}_{40}\right]^{3-}$, can be described as an assembly of a central tetrahedron of oxygen, the center of which is occupied by phosphorus and 4 peripheral $\left[\mathrm{W}_{3} \mathrm{O}_{13}\right]$ blocks that complete 12 octahedra in total, the centers of which are occupied by tungsten (see Figure 2 , a). In each $\left[\mathrm{W}_{3} \mathrm{O}_{13}\right]$ block, three octahedra are connected by an edge of oxygen atoms and each block shares an oxygen atom with each of the other blocks as well as the central tetrahedron. This (a)

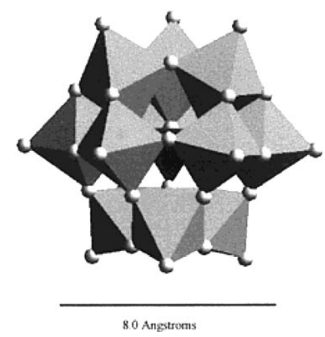

(b)

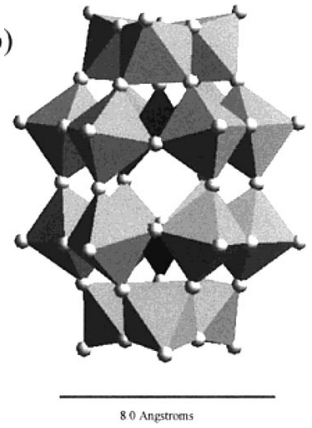

Figure 2. Polyhedral representations of the molecular structures of (a) plenary Keggin-type $\left[\mathrm{PW}_{12} \mathrm{O}_{40}\right]^{3-}$ and (b) Wells-Dawson-type $\left[\mathrm{P}_{2} \mathrm{~W}_{18} \mathrm{O}_{62}\right]^{6-}$ heteropolyanions. Reproduced with permission from ref. ${ }^{[16]}$ Copyright 2002 American Chemical Society.

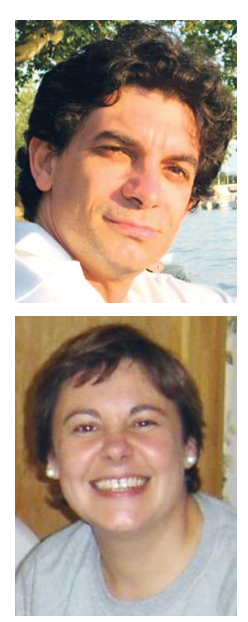

Giuseppe Marcì received his BS degree in Chemical Engineering (1992) and his PhD degree (1996) from the Engineering School at Palermo University. Since 1997, he has been an Assistant Professor in Chemistry at the University of Palermo, where he teaches chemistry and develops his work in the fields of photocatalysis and materials chemistry. He is a coauthor of 92 scientific papers ( $h$ index 28, SCOPUS, July 2013).

Elisa García-López was born in Madrid. She obtained her BS degree in Chemistry from Universidad Autónoma de Madrid (1993). She then worked in the "Instituto de Catálisis y Petroleoquimica" (CSIC, Spain) and CIEMAT (Spain). In 1998, she moved to the Università di Palermo (Italy). She then became an Assistant Professor in Chemistry and a Chemistry Lecturer at the Engineering School of Palermo University (2001). She obtained her PhD degree in Chemistry and Materials Science in 2003. She was an invited researcher at Meisei University (Tokyo, Japan) with Prof. Hidaka (2006-2007). The main focus of her scientific work is devoted to heterogeneous photocatalysis. She is the coauthor of 56 scientific papers ( $h$ index 22, SCOPUS, July 2013).

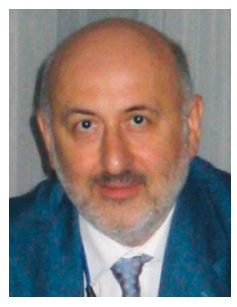

Leonardo Palmisano is a Full Professor of Chemistry at the University of Palermo. His main field of interest is heterogeneous photocatalysis. He is the coauthor of ca. 300 papers published in international journals and books and the coauthor of several oral or poster presentations at national and international conferences. He has been invited as a visiting researcher (Bradford University, UK), visiting professor (Hokkaido University, Japan), and lecturer at many universities all over the world. He is also the coauthor of the didactic book "Fondamenti di Chimica" published in Italy by Edises and in Spain by Ariel Ciencia. His papers have received about 7400 citations (h index 46, SCOPUS, July 2013). 
cluster has a diameter of ca. $1.2 \mathrm{~nm} \cdot{ }^{[14]}$ The lack of one (monovacant) or more addenda atoms results in the formation of the "lacunary" HPAs, in contrast to the "plenary" ones. The current research is often focused on functionalization of HPAs to covalently attach these clusters to organic or inorganic species. For that aim, the first step is the removal of one or several metal "octahedra" from the original HPA to generate the lacunary species. In non-lacunary (plenary) HPAs, the negative charge is delocalized over the entire structure, whereas in lacunary HPAs, the oxygen atoms are more nucleophilic and hence more reactive towards electrophilic organic and inorganic groups to form covalent bonds, as discussed below. The lacunary HPAs can also assemble to form new species. The Wells-Dawson anion may be considered to be derived from the Keggin one by removing one $\left[\mathrm{M}_{3} \mathrm{O}_{9}\right]$ block from each Keggin anion and by linking them through oxygen atoms to form a nearly ellipsoidal anion cluster ${ }^{[15]}$ (see Figure 2, b).

In general, HPAs are prepared in aqueous medium by acidification, but the preparation conditions can give rise to a large family of compounds. The variables are: (1) concentration/type of metal oxide anions, (2) $\mathrm{pH}$ and type of acid, (3) type and concentration of electrolyte, (4) heteroatom concentration, (5) possibility to introduce additional ligands, (6) reducing agent, (7) temperature and solvent. ${ }^{[12]}$ As an example, the Keggin cluster can be obtained by a simple polycondensation reaction in an acidic medium between the phosphate (or silicate) and tungstate ions:

$\mathrm{PO}_{4}{ }^{3-}+12 \mathrm{WO}_{4}{ }^{2-}+24 \mathrm{H}^{+} \rightarrow \mathrm{PW}_{12} \mathrm{O}_{40}{ }^{3-}+12 \mathrm{H}_{2} \mathrm{O}$

The heteropolyanion itself forms the so-called primary structure (Figures 2 and 3, a), whereas in the solid material we can find anions, countercations, and also some polar molecules, such as water and alcohols. The secondary structure is formed by the union of several primary units, and the assembly is neutralized by countercations $\left(\mathrm{H}^{+}\right.$or monovalent cations such as $\mathrm{Na}^{+}, \mathrm{NH}_{4}^{+}$, and $\mathrm{Cs}^{+}$). The primary structure forms secondary rather than mobile structures by interacting with polar molecules such as water, which are present in the bulk of crystallites, and this gives rise to the protonated clusters (see Figure $3, \mathrm{~b}$ ). The primary structures of $\mathrm{H}_{3} \mathrm{PW}_{12} \mathrm{O}_{40}$ and $\mathrm{H}_{6} \mathrm{P}_{2} \mathrm{~W}_{18} \mathrm{O}_{62}$ present molecular dimensions of ca. $11.7 \times 11.7$ and $11.2 \times 14.4 \AA$, respec-

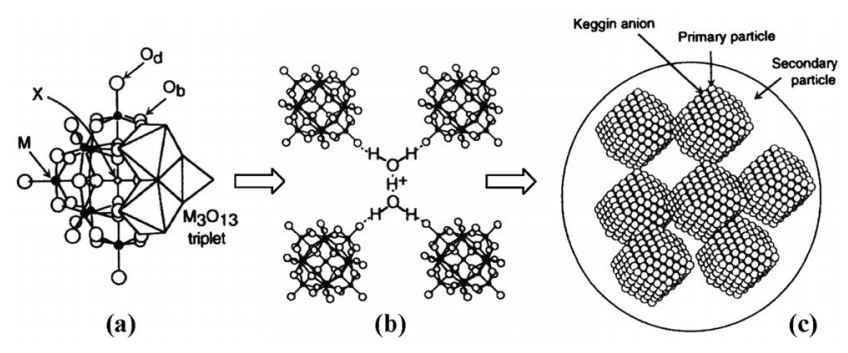

Figure 3. Structural hierarchy of heteropoly compounds: (a) Keggin cluster (primary particle), (b) secondary structure, and (c) tertiary structure (texture: particle size, porosity, surface area, etc.). Adapted from ref. ${ }^{[14 c]}$ with permission of The Royal Society of Chemistry. tively. ${ }^{[16]}$ The secondary structures condense into small particles of different sizes that can exceed several tens of nanometers. The $\mathrm{H}^{+}$countercation appears as a protonated dimer of water in the form of dioxonium $\mathrm{H}_{5} \mathrm{O}_{2}{ }^{+}$. Each $\mathrm{H}_{5} \mathrm{O}_{2}{ }^{+}$ links four $\left[\mathrm{PW}_{12} \mathrm{O}_{40}\right]^{3-}$ anions, which results in the formation of hydrogen bonds involving the terminal $\mathrm{O}$ atoms, ${ }^{[17]}$ as reported in Figure 3 (b).

The presence of water in the secondary structure is of paramount importance, for instance in considering the use of HPAs as catalysts, because it influences the acidity and the adsorption properties and, hence, their catalytic activity ${ }^{[14]} \mathrm{HPAs}$ contain up to $30 \mathrm{H}_{2} \mathrm{O}$ molecules of crystallization per anion, which desorb progressively by increasing the temperature. The solid becomes completely dehydrated at ca. $350-500{ }^{\circ} \mathrm{C}$. Dioxonium is removed at ca. 150 $200{ }^{\circ} \mathrm{C}^{[17]} \mathrm{HPAs}$ are thermally unstable, and in particular, the thermal stability of the Keggin structure decreases in the following order: $\mathrm{H}_{3}\left[\mathrm{PW}_{12} \mathrm{O}_{40}\right]>\mathrm{H}_{3}\left[\mathrm{SiW}_{12} \mathrm{O}_{40}\right]>$ $\mathrm{H}_{3}\left[\mathrm{PMo}_{12} \mathrm{O}_{40}\right]>\mathrm{H}_{3}\left[\mathrm{SiMo}_{12} \mathrm{O}_{40}\right]$, but it can be enhanced by the formation of appropriate salts. ${ }^{[18]}$ HPAs possess strong acidity both in the solid state and in solution, and this can be attributed to the large dimensions of the polyanion, which favor the delocalization of protons within the structure. The order of acidity for the Keggin anions is the following: $\mathrm{H}_{3}\left[\mathrm{PW}_{12} \mathrm{O}_{40}\right]>\mathrm{H}_{3}\left[\mathrm{SiW}_{12} \mathrm{O}_{40}\right] \geq \mathrm{H}_{3}\left[\mathrm{PMo}_{12} \mathrm{O}_{40}\right]>$ $\mathrm{H}_{3}\left[\mathrm{SiMo}_{12} \mathrm{O}_{40}\right],{ }^{[19]}$ and the acidity strength in the available surface of the solid HPAs depends on the nature of the countercation. If this anion is small (as for $\mathrm{Na}^{+}$), the behavior of the HPA is very similar to that of the acidic form and the species is thus highly soluble in water and polar solvents; conversely, if this anion is voluminous (as for $\mathrm{K}^{+}$, $\mathrm{Cs}^{+}, \mathrm{NH}_{4}{ }^{+}$), the HPAs are insoluble in water. The usable acidity for a (photo)catalytic reaction depends on the size of particles (tertiary structure, Figure 3, c). In most cases, the reagent molecules cannot penetrate into the tertiary structure, and only a small fraction of the total acidity is accessible. However, owing to the ability of HPAs to solve polar molecules, the latter can react more easily (reaction in "pseudo-liquid phase"). ${ }^{[14]}$ Another important feature of many HPAs, particularly the Keggin and Wells-Dawson structures, is that they are reduced easily and reversibly under mild conditions, and consequently, they have been used as catalysts in oxidation reactions. They accept one or more electrons to form mixed-valence species, the so-called "heteropolyblues" that retain the structure of the parent oxidized anions. ${ }^{[18]}$

HPAs have been actively studied in catalysis, in solution, and in the solid state as a result of their good activity in acid and oxidation catalysis. The long list of review articles and special issues devoted to this field published in the last decades ${ }^{[20]}$ along with several patents and the commercialization of several catalytic processes involving HPAs are clear indications of their practical significance. Owing to the low specific surface area $\left(1 \div 10 \mathrm{~m}^{2} \mathrm{~g}^{-1}\right)$ of unsupported HPAs, heterogenization of these clusters for catalytic purposes is advantageous; in fact, their dispersion on supports with high surface areas increases the accessibility to their acidic sites and consequently increases their catalytic ac- 
tivity. Moreover, as most of the HPAs are very soluble in water and polar solvents, their heterogenization allows them to be used in a liquid-solid regime with successive recovery and recycling of the solid photocatalyst. The classical strategy for heterogenizing the HPA clusters consists in supporting them on an oxide. Recently, heterogenized HPAs were prepared associated with inorganic, organic, and organometallic moieties. The supported HPAs evidenced important changes in structure, acid strength, and redox properties with respect to the unsupported material. For instance, the most studied plenary Keggin HPAs were supported on several oxides, such as $\mathrm{SiO}_{2},{ }^{[21-25]} \mathrm{Al}_{2} \mathrm{O}_{3},{ }^{[26,27]} \mathrm{ZrO}_{2},{ }^{[28,29]}$ and $\mathrm{Ta}_{2} \mathrm{O}_{5}{ }^{[30]}$ and on carbon. ${ }^{[21,31]}$ Silica is widely favored as a support, because it interacts weakly with the Keggin anions, and thus their structures are preserved. Conversely, interaction with basic solids, such as $\mathrm{MgO}, \mathrm{ZnO}$, and $\mathrm{Al}_{2} \mathrm{O}_{3}$, induces their decomposition, which results in a decrease in acidity. ${ }^{[32]}$ Detrimental effects of such interactions on catalytic activity have also been documented. ${ }^{[25-27,33]}$ In addition, HPAs have also been extensively studied as photocatalysts in homogeneous systems. ${ }^{[34]}$ In fact, absorption of light by the ground electronic state of the solubilized HPA produces an excited-state HPA* Light absorption gives rise to a $\mathrm{O} \rightarrow \mathrm{M}$ ligand-to-metal charge transfer (LMCT) in the HPA cluster. For instance, in the tungstophosphate Keggin structure from an $\mathrm{O}^{2-}$ to a $\mathrm{W}^{6+}$ at $\mathrm{W}-\mathrm{O}-\mathrm{W}$ bonds, an electron is promoted from a spin paired, doubly occupied bonding orbital (HOMO) to an empty, antibonding orbital (LUMO), and this results in the generation of a species with a hole center $\left(\mathrm{O}^{-}\right)$and a trapped electron center $\left(\mathrm{W}^{5+}\right)$. This charge transfer observed at $260 \mathrm{~nm}$, corresponding to $4.8 \mathrm{eV}$, for the plenary Keggin $\mathrm{H}_{3}\left[\mathrm{PW}_{12} \mathrm{O}_{40}\right]$ is qualitatively analogous to the band gap of a solid semiconductor metal oxide that also generates an electron-hole pair under irradiation. ${ }^{[35]}$ The proposed mechanism of the HPA-based photocatalysis involves several steps. ${ }^{[34]}$ First, there is preassociation between the HPA and the substrate (S), which is followed by absorption of light by the formed complex, and this results in the formation of the excited-state species (HPA*) with a high reduction potential. In the presence of an electron donor (substrate S), the latter gives rise to the well-known heteropolyblue reduced form ( $\left.\mathrm{HPA}^{-}\right)$that absorbs at $650 \mathrm{~nm}$ [see Eq. (2)-(4)]. The next step is the reoxidation of HPA- upon exposure to an oxidant, for instance, $\mathrm{O}_{2}$ [Eq. (5)].

$\mathrm{HPA}+\mathrm{S} \rightarrow(\mathrm{HPA}-\mathrm{S})$

$($ HPA-S $)(\lambda<400 \mathrm{~nm}) \rightarrow\left(\mathrm{HPA}^{*}-\mathrm{S}\right)$

$\left(\mathrm{HPA}^{*}-\mathrm{S}\right) \rightarrow \mathrm{HPA}^{-}+\mathrm{S}^{++}$

$\mathrm{HPA}^{-}+\mathrm{O}_{2} \rightarrow \mathrm{HPA}+\mathrm{O}_{2}^{-}$

The formation of highly reactive $\mathrm{OH}$ radicals was proposed to enhance photooxidation performance according to Equations (6)-(8).

$\mathrm{O}_{2}^{--}+\mathrm{H}_{2} \mathrm{O} \rightarrow \mathrm{HO}_{2}{ }^{-}+\mathrm{OH}^{-}$

$2 \mathrm{HO}_{2} \rightarrow \mathrm{O}_{2}+\mathrm{H}_{2} \mathrm{O}_{2}$
$\mathrm{O}_{2}^{\cdot-}+\mathrm{H}_{2} \mathrm{O}_{2} \rightarrow \cdot \mathrm{OH}+\mathrm{OH}^{-}+\mathrm{O}_{2}$

Oxidizing species of the type $\mathrm{OH}$ have been experimentally detected in the presence of HPAs by photolysis and electron paramagnetic resonance (EPR) experiments. The reoxidation of the HPA catalyst to its original oxidation state [Eq. (5)] was reported to be the rate-determining step in the photocatalytic cycle of the HPAs, ${ }^{[36]}$ and it is performed by an electron acceptor such as $\mathrm{O}_{2}$ dissolved in the suspension or in the absence of $\mathrm{O}_{2}$ by other electrophilic species. ${ }^{[37]}$

In this microreview the reported literature on the use of HPA-based materials as heterogeneous photocatalysts for environmental purposes is presented, in particular for complete or partial oxidation or reduction of organic molecules. Notably, HPAs or nanohybrids of inorganic nanosheets and POMs have been also widely used for the photosplitting of water ${ }^{[38]}$ and for the reduction of noble metals to prepare nanoclusters, ${ }^{[39]}$ but we refer readers to papers recently published to obtain detailed information.

\section{Types of HPA-Based Heterogeneous Photocatalysts}

\section{HPA Supported on Different Oxides}

The methodologies devoted to heterogenize HPAs by supporting them on different oxides can be divided in two main groups, that is, those in which the HPA is supported on a photocatalytically inactive support and those in which the HPA is supported on a photocatalytically active support. In the latter composites, the concomitant excitation of both the HPA and the support, generally a semiconductor oxide, enhances the photoactivity of the powder as a whole. Several techniques have been used by various authors to prepare their HPA-supported samples, but generally, the most frequently used were the sol-gel and impregnation methods. We will discuss first the literature regarding HPAs supported on photocatalytically inactive materials. Notably, for these kinds of composites the mechanism of the photocatalytic process is that explained in the previous section for homogeneous systems. In these composite materials, the support can play the double role of modifying some of the physicochemical features of the HPA and of improving the adsorption ability of the substrates to react with the active species. Guo et al. reported ${ }^{[40]}$ the use of $\mathrm{H}_{3} \mathrm{PW}_{12} \mathrm{O}_{40} / \mathrm{SiO}_{2}$ and $\mathrm{H}_{4} \mathrm{SiW}_{12} \mathrm{O}_{40} / \mathrm{SiO}_{2}$ prepared by incorporating the HPAs into a silica matrix through a sol-gel technique. The photocatalytic activity of the composites was tested by degradation of malic acid, which was totally mineralized in ca. $2 \mathrm{~h}$ by irradiation with UV light. Intermediate products identified by using supported HPAs or bare $\mathrm{TiO}_{2}$ were the same, and this indicated that in both systems the ${ }^{\circ} \mathrm{OH}$ radical was the main oxidant, as reported in Equations (2)-(8) and Figure 1. Alternatively, the authors used amine-functionalized silica as a support for a transition-metal-substituted polyoxometalate (TMSP). ${ }^{[41]}$ TMSPs are considered as inorganic porphyrins consisting 
of clusters in which one of the addenda transition metals of the HPA is coordinated to five oxygen atoms, and the sixth coordination site is occupied by a water molecule. The water molecule of most TMSPs can be displaced in aqueous media by ligands such as pyridines and ammonia. Moreover, Guo et al. replaced a $\mathrm{W}^{\mathrm{VI}}$ addenda atom with a $\mathrm{Ni}^{\mathrm{II}}$. The TMSP $\left[\mathrm{Ni}\left(\mathrm{H}_{2} \mathrm{O}\right) \mathrm{SiW}_{11} \mathrm{O}_{39}\right]$, called $\left(\mathrm{SiW}_{11} \mathrm{Ni}\right)$, was covalently coordinated by the Ni centers to the amine surface groups of the silica. Rhodamine B dye was completely mineralized by using this heterogeneous photocatalyst and no $\left(\mathrm{SiW}_{11} \mathrm{Ni}\right)$ leaching was observed. The authors compared the photocatalytic activity of solubilized $\left(\mathrm{SiW}_{11} \mathrm{Ni}\right)$ with that of heterogenized $\left(\mathrm{SiW}_{11} \mathrm{Ni}\right)$, and they reported an improvement with the use of the supported material. However, according to Guo et al., although the photocatalytic activity of the plenary HPAs was higher than that of the lacunary HPA or TMSP, the use of the latter was preferable owing to the strong chemical interaction with the matrix, which prevents leaching. Shen et al. reported the use of $\mathrm{H}_{3} \mathrm{PW}_{12} \mathrm{O}_{40} / \mathrm{MCM}-41$ supported by impregnation of fluorinated Si-MCM-41 for the selective oxidation of alcohols to aldehydes in ionic liquids (ILs). ${ }^{[42]}$ The photocatalytic activity of this material was higher than that of the bare HPA. The authors observed an optimal loading of $30 \mathrm{wt}$ $\%$ for the HPA. The use of ILs instead of $\mathrm{CH}_{3} \mathrm{CN}$ also improved the reactivity. Imidacloprid pesticide was partially degraded $(58.0 \%)$ after $5 \mathrm{~h}$ of irradiation at $365 \mathrm{~nm}$ by using $\mathrm{H}_{3} \mathrm{PW}_{12} \mathrm{O}_{40} / \mathrm{MCM}-41$, prepared by impregnation with an HPA loading of 50 wt. $-\%{ }^{[43]} \mathrm{H}_{3} \mathrm{PW}_{12} \mathrm{O}_{40}$ was also anchored to amino-functionalized $\mathrm{Fe}_{3} \mathrm{O}_{4} / \mathrm{SiO}_{2} /$ meso- $\mathrm{SiO}_{2}$ microspheres by means of chemical bonds to aminosilane groups. The resultant microspheres contained an HPA loading of ca. $17 \mathrm{wt} .-\%$ and rhodamine B was degraded under UV irradiation more quickly than the solubilized HPA, with the further advantage that the photocatalyst could be magnetically recovered. ${ }^{[44]}$ The authors pointed out that the HPA interacts with the silica support through an acid-base reaction and hydrogen and covalent bonds between $-\mathrm{NH}_{2}$ and $\mathrm{H}_{3} \mathrm{PW}_{12} \mathrm{O}_{40}$; however, they admitted that leaching of the HPA unit was inevitable. Ozer and Ferry used NaY zeolite along with $\mathrm{H}_{2} \mathrm{NaPW}_{12} \mathrm{O}_{40}, \mathrm{H}_{4} \mathrm{SiW}_{12} \mathrm{O}_{40}$, and $\mathrm{H}_{3} \mathrm{PMo}_{12} \mathrm{O}_{40}$ as photocatalysts for the degradation of 1,2dichlorobenzene. ${ }^{[45]}$ In this case, the authors did not heterogenize the HPA, but they added it to the zeolite suspension in the photocatalytic reactor. They attributed an important role to the zeolite surface for the enhancement in the photocatalytic degradation rate of the substrate. Indeed, the authors claimed that the zeolite surface enhances the "local concentration" of both the substrate and the excited HPA, which consequently can react more efficiently in the adsorbed phase. Moreover, according to Ozer and Ferry the zeolite surface stabilizes charge-transfer states and transient species as ${ }^{\circ} \mathrm{OH}$. Recently, Pizzio et al. ${ }^{[46]}$ prepared two series of materials based on $\mathrm{H}_{3} \mathrm{PW}_{12} \mathrm{O}_{40}$ immobilized on $\mathrm{NH}_{4} \mathrm{Y}$ and $\mathrm{NH}_{4} \mathrm{ZSM} 5$ zeolites. These materials were prepared by wet impregnation of the zeolite matrix with the HPA aqueous solutions with a loading in the range from 5 to $30 \mathrm{wt}$.$\%$. The Keggin anion was partially transformed into
$\left[\mathrm{P}_{2} \mathrm{~W}_{21} \mathrm{O}_{71}\right]^{6-}$ during the synthesis and soft drying (vacuum at $80^{\circ} \mathrm{C}$ ). The acid properties of both series of composites were rather similar, despite the higher acid strength of $\mathrm{NH}_{4}$ ZSM5. The samples with the highest HPA content presented band-gap energy values similar to those reported for $\mathrm{TiO}_{2}$. Consequently, the authors concluded that these materials were active for the photocatalytic degradation of 4chlorophenol in a liquid-solid regime carried out by using a $125 \mathrm{~W}$ high-pressure mercury lamp as the irradiation source. The increase in the photocatalytic activity by increasing the amount of the HPA was attributed to the direct participation of the HPA in the degradation of the organic substrate [Eqs. (2)-(8)]. Moreover, lowering of the band-gap values for the composites with higher HPA content can increase the absorption capacity of radiation with lower energy.

As far as the HPAs supported on photocatalytically active semiconductors are concerned, the activity of the heterogenized HPAs is further enhanced if $\mathrm{TiO}_{2}$ is used as a support. Heterogenized HPA enhances the activity by acting as an electron scavenger, which results in a delay in the recombination of $\mathrm{h}^{+}$and $\mathrm{e}^{-}$pairs, ${ }^{[35]}$ and by catalyzing the photodegradation of the substrate by means of $\mathrm{HPA}^{-}$, which can react with molecular oxygen or another electrophilic species ${ }^{[36]}$ (see Figure 4). The Keggin-type HPA supported on $\mathrm{TiO}_{2}$ has been the most studied photocatalyst. A perusal of Figure 4 shows how the semiconductor directly transfers the photogenerated electrons from the conduction band to the HPA* formed by excitation of the HPA [see Eq. (3)]. The Keggin anion $\left[\mathrm{PW}_{12} \mathrm{O}_{40}\right]^{3-*}$, from a thermodynamic point of view, is a better electron acceptor than $\mathrm{O}_{2}$ $[+0.22$ ( $\mathrm{pH}$ independent) and $-0.33 \mathrm{~V}$ (at $\mathrm{pH} 0$ ) vs. NHE, respectively]. ${ }^{[47]}$ Notably, the reduction potential of $\left[\mathrm{PW}_{12} \mathrm{O}_{40}\right]^{3-*}$ is more positive than the flatband potential of the conduction band of $\mathrm{TiO}_{2}$ particles [ca. $-0.19 \mathrm{~V}$ vs. NHE (at pH 0)]. ${ }^{[48]}$

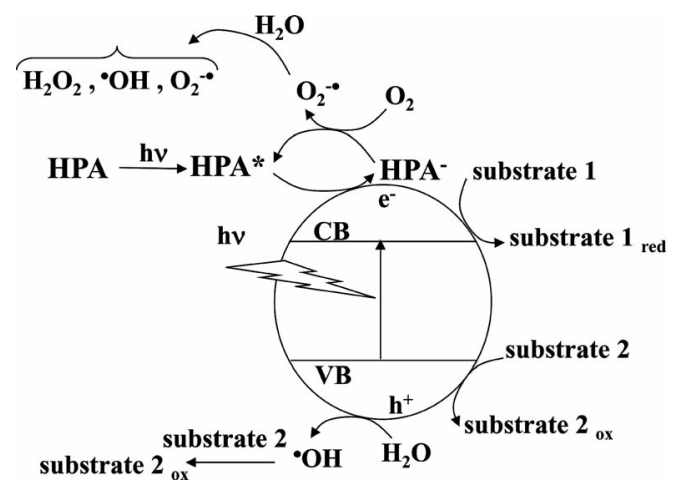

Figure 4. Mechanism showing the synergy between a HPA and a photocatalytically active semiconductor under irradiation.

In this way the electron transfer from the conduction band of $\mathrm{TiO}_{2}$ to $\left[\mathrm{PW}_{12} \mathrm{O}_{40}\right]^{3-*}$ is thermodynamically favorable to yield $\left[\mathrm{PW}_{12} \mathrm{O}_{40}\right]^{4-}$ species. The enhanced degradation in the organic compounds by using HPAs on semiconductor oxides in the presence of UV light has been, on this basis, thoroughly explained in the literature. 
Yoon et al. suggested that such a reaction scheme with a double electron-transfer mechanism resembles the "Zscheme" mechanism invoked in the photosynthesis process. ${ }^{[49]}$ Tachikawa et al. ${ }^{[50]}$ experimentally demonstrated the one-electron oxidation and reduction processes reported in Figure 4 in the HPA-mediated $\mathrm{TiO}_{2}$ photocatalytic reaction by using the two-color two laser flash photolysis technique. ${ }^{[50]}$ The efficiency of this electron transfer increased by using $\mathrm{PW}_{12} \mathrm{O}_{40}{ }^{3-}$ instead of $\mathrm{SiW}_{12} \mathrm{O}_{40}{ }^{4-}$. They attributed this behavior to the reduction potentials of the two different HPAs. ${ }^{[47]}$ Also, the ability of the HPA to act as an acceptor of the electrons generated in the conduction band of UVirradiated $\mathrm{TiO}_{2}$ suspensions was demonstrated by Park and Choi ${ }^{[35]}$ by using a photoelectrochemical method. The timeresolved microwave conductivity (TRMC) technique also helps to demonstrate electronic transitions from the semiconductor to the HPA. It gives information on the lifetimes of charge carriers created on the semiconductor and upon recombination and/or trapping phenomena. We experimentally observed that the Keggin HPA has a favorable effect on the charge carrier separation in the photocatalytic process when it is supported on both $\mathrm{TiO}_{2}$ and $\mathrm{WO}_{3}{ }^{[51]}$

The use of HPAs heterogenized on $\mathrm{TiO}_{2}$ in the powder form has been extensively studied in the liquid-solid regime for several photocatalytic model reactions. In general, it was reported that the primary Keggin and Dawson structures remained intact after immobilization on or inside the $\mathrm{TiO}_{2}$ network. The authors explained the increasing activity of the composite material with respect to the homogeneous HPA or bare semiconductor in the terms above exposed (Figure 4), that is, interfacial electron transfer from the conduction band of $\mathrm{TiO}_{2}$ to the incorporated HPA, reduction of the HPA after its activation by UV light and, hence, oxidation of the reduced HPA species to give rise to $\mathrm{OH}$ radicals. In one of the first attempts to understand this composite system, Yoon et al. prepared a $\mathrm{HPA} / \mathrm{TiO}_{2}$ reacting medium by incorporating $\mathrm{H}_{3} \mathrm{PW}_{12} \mathrm{O}_{40}$ into a polyvinyl alcohol $\mathrm{TiO}_{2}$ colloidal suspension and illuminated their system with UV light (300-375 nm) for the photodegradation of methyl orange. ${ }^{[48]}$ Even if the HPA was not heterogenized but added to the $\mathrm{TiO}_{2}$ suspension, the photodecompositon yield increased linearly with the concentration of the HPA and also with the amount of colloidal $\mathrm{TiO}_{2}$. The extent of the photoinduced reaction depended also on the irradiation wavelength and intensity. According to Yoon et al., the photoinduced charge-carrier generation at the $\mathrm{HPA}-\mathrm{TiO}_{2}$ heterojunction was very efficient and was also enhanced upon illumination of the HPA-incorporated $\mathrm{TiO}_{2}$ with visible light as well as near-UV light. In an analogous way, Ozer et al. ${ }^{[52]}$ added $\mathrm{PW}_{12} \mathrm{O}_{40}{ }^{3-}$ and $\mathrm{SiW}_{12} \mathrm{O}_{40}{ }^{4-}$ to a $\mathrm{TiO}_{2}$ suspension. In the presence of $\mathrm{O}_{2}$, the addition of HPA anions to $\mathrm{TiO}_{2}$ suspensions resulted in a significant rate enhancement for 1,2-dichlorobenzene oxidation. The reduction potentials of the HPA used by these authors were $+0.219 \mathrm{~V}$ vs. NHE for $\mathrm{H}_{2} \mathrm{NaPW}_{12} \mathrm{O}_{40}{ }^{[53]}$ and $+0.055 \mathrm{~V}$ vs. NHE for $\mathrm{H}_{4} \mathrm{SiW}_{12} \mathrm{O}_{40} \cdot{ }^{\left[{ }^{[5]}\right.} \mathrm{HPAs}$ as oxidants are more effective than $\mathrm{O}_{2}$ to remove conduction band electrons from $\mathrm{TiO}_{2} \cdot{ }^{[52]}$
Mixtures of $\mathrm{H}_{3} \mathrm{PW}_{12} \mathrm{O}_{40}$ with commercial $\mathrm{TiO}_{2}$ Degussa P25 were used for 2,4-dichlorophenol photocatalytic degradation in aqueous media. ${ }^{[5]} \mathrm{H}_{3} \mathrm{PW}_{12} \mathrm{O}_{40}$ species on the surface of $\mathrm{TiO}_{2}$ accelerated the hydroxylation of the substrate but not its mineralization, which was somewhat suppressed in the presence of the HPA. An increase in the loading of the HPA increased the concentration of the toxic intermediates. This important result indicates that an enhancement in charge separation in $\mathrm{TiO}_{2}$ photocatalysis does not always result in an improvement in the efficiency of mineralization of organic substrates.

Guo's group has intensively worked in this field. ${ }^{[56-61]} \mathrm{A}$ composite material prepared as a hydrogel by mixing titanium isopropoxide with a $\mathrm{H}_{3} \mathrm{PW}_{12} \mathrm{O}_{40}$ solution was used. The material was successively autoclaved and calcined. The resultant $\mathrm{H}_{3} \mathrm{PW}_{12} \mathrm{O}_{40} / \mathrm{TiO}_{2}$ photocatalytically decolorized 10 various organic dyes in aqueous systems under visiblelight irradiation $(\lambda>420 \mathrm{~nm}) .{ }^{[56]}$ The authors claimed that the introduction of the HPA into the $\mathrm{TiO}_{2}$ framework resulted in changes in the coordination environment of crystalline $\mathrm{TiO}_{2}$ and, hence, in the band-gap value. The interfacial electron transfer from the $\mathrm{TiO}_{2}$ conduction band to the HPA occurred under visible-light irradiation. An electrostatic interaction between the HPA and $\mathrm{TiO}_{2}$ occurred during the hydrolysis of titanium tetraisopropoxide in the presence of the Keggin ion that remained entrapped by the protonated hydroxy groups on the $\mathrm{TiO}_{2}$ surface $(\equiv \mathrm{Ti}-\mathrm{OH})$, and this resulted in interactions between $\left(\equiv \mathrm{TiOH}_{2}{ }^{+}\right)$and $\left(\mathrm{H}_{2} \mathrm{PW}_{12} \mathrm{O}_{40}{ }^{-}\right)$. Moreover, hydrogen bonds were formed between the oxygen atoms of the Keggin ion and the hydroxy groups of the $\mathrm{TiO}_{2}$ surface (WO $\cdots \mathrm{HO}-\mathrm{Ti}$ ). The authors attributed the photocatalytic activity not only to the synergistic effect of the HPA on the semiconductor oxide, expressed by the mechanism reported in Figure 4, but also to the porous structure of the nanocomposite that enhanced mass transport and increased adsorption of the reactants. An important point was that these experiments were performed under visible-light irradiation. The mineralization was not systematically followed, but some intermediates were identified along with the presence of some final products such as $\mathrm{NH}_{4}{ }^{+}, \mathrm{SO}_{4}{ }^{2-}, \mathrm{NO}_{3}^{-}$, and $\mathrm{Cl}^{-}$. The same research group prepared Keggin $\mathrm{H}_{3} \mathrm{PW}_{12} \mathrm{O}_{40}$ and Wells-Dawson $\mathrm{H}_{6} \mathrm{P}_{2} \mathrm{~W}_{18} \mathrm{O}_{62}$ on $\mathrm{TiO}_{2}$ by using their usual preparation methods (combination of sol-gel and hydrothermal processes), analogously to that reported in ref. ${ }^{[56]}$ ). The powders were, also in this case, characterized by a narrow band gap and were nanometers in size. ${ }^{[57]}$ They were used in the visible-light photocatalytic degradation of parathion-methyl insecticide. The authors attributed the activity of both composites to the synergistic effect between the HPA and $\mathrm{TiO}_{2}$ but also to the narrow band gap and porous structures. They loaded a series of Keggin HPAs with different heteroatoms, that is, $\left[\mathrm{X}^{n+} \mathrm{W}_{12} \mathrm{O}_{40}\right]^{(8-n)-}$, in which $\mathrm{X}^{n+}=\mathrm{P}^{5+}, \mathrm{Si}^{4+}$, $\mathrm{Ge}^{4+}$ onto $\mathrm{TiO}_{2}$. Interestingly, no thermal treatment followed in this case. ${ }^{[58]}$ These materials showed higher photocatalytic activity under visible light than both bare $\mathrm{TiO}_{2}$ and the HPAs (or a mechanical mixture of the two) for the degradation of the dye reactive brilliant red X-3B (followed 
by dye bleaching). Two variables influenced the reaction rate of bleaching: the HPA loading $(30>15>45$ wt.- $\%)$ and the presence of different heteroatoms in the HPA $(\mathrm{P}>\mathrm{Si}>\mathrm{Ge})$. The authors reported that their HPAs were better dispersed in $\mathrm{TiO}_{2}$ by the sol-gel method than by incipient wetness impregnation, but they did not give any explanation for this behavior. The same group also used $\mathrm{Cs}_{x} \mathrm{H}_{3-x} \mathrm{PW}_{12} \mathrm{O}_{40} / \mathrm{TiO}_{2}(x=0.5$ to 3.0$)$, prepared through a combination of sol-gel and hydrothermal processes, for the photocatalytic degradation of 4-nitrophenol, methyl orange, and rhodamine B under UV irradiation by following both the total organic carbon concentration and the substrate degradation. ${ }^{[59]}$ The composites were more effective than the bare $\mathrm{Cs}_{x} \mathrm{H}_{3-x} \mathrm{PW}_{12} \mathrm{O}_{40}$ or $\mathrm{TiO}_{2}$ Degussa P25, particularly the material with $x=2.5$. The photoactivities were attributed to higher surface acidity, the mesoporosity, and the synergistic effect between the HPA and $\mathrm{TiO}_{2} . \mathrm{H}_{3} \mathrm{PW}_{12} \mathrm{O}_{40}$ was also deposited on mesoporous $\mathrm{TiO}_{2}$ (3.2 to $16.6 \mathrm{wt} . \mathrm{\%} \%$ loadings). The preparation method included both sol-gel (in the presence of a template, Pluronic 123) and hydrothermal treatments to obtain a well-distributed 3D interconnected mesopore structure, partially covered by the HPA. ${ }^{[60]}$ The solid acted as a photocatalyst for the degradation/mineralization of dyes, that is, methyl orange, methylene blue, crystal violet, and rhodamine $\mathrm{B}$, under UV light. The $\mathrm{H}_{3} \mathrm{PW}_{12} \mathrm{O}_{40} / \mathrm{TiO}_{2}$ composite material prepared by Guo et al. by their usual method was also successfully applied to the degradation/mineralization of aqueous phthalate esters, di- $n$-butyl phthalate (DBP), diethyl phthalate (DEP), and dimethyl phthalate (DMP), under simulated sunlight irradiation (Xe lamp) ${ }^{[61]}$ Degradation of DBP, DEP, and DMP reached 98, 84, and 80\%, respectively, after $90 \mathrm{~min}$, and nearly total mineralization of DBP and DEP was achieved after a reaction time of $12 \mathrm{~h}$. The authors attributed the photocatalytic performance of these composites to a synergistic effect between the Keggin unit and the $\mathrm{TiO}_{2}$ network. The synergism can be explained not only by considering the presence of $\mathrm{OH}, \mathrm{h}^{+}$, and $\mathrm{O}_{2}{ }^{-}$ formed under irradiation of the $\mathrm{HPA} / \mathrm{TiO}_{2}$ samples (see Figure 4) but also by the pore morphology of the photocatalyst that favored the adsorption of the substrate. The successful use of simulated sunlight irradiation depended on the kind of $\mathrm{HPA} / \mathrm{TiO}_{2}$ composite, but it was not satisfactorily clarified. Notably, the absorption of light and the photoreactivity could also be related to the type of molecule used, and in particular to surface complexes activated by visible light, as reported by Choi. ${ }^{[62]}$ Guo et al. also prepared saturated and monovacant Keggin unit functionalized $\mathrm{TiO}_{2}$ materials, $\mathrm{H}_{3} \mathrm{PW}_{12} \mathrm{O}_{40} / \mathrm{TiO}_{2}$, and $\mathrm{K}_{7} \mathrm{PW}_{11} \mathrm{O}_{39} /$ $\mathrm{TiO}_{2}$ by one-step sol-gel co-condensation followed by solvothermal treatment. Simulated sunlight photocatalysis of rhodamine $\mathrm{B}$ and diethyl phthalate were used as test reactions. ${ }^{[63]} \mathrm{H}_{3} \mathrm{PW}_{12} \mathrm{O}_{40} / \mathrm{TiO}_{2}$ and $\mathrm{K}_{7} \mathrm{PW}_{11} \mathrm{O}_{39} / \mathrm{TiO}_{2}$ showed better photocatalytic performance with respect to bare $\mathrm{TiO}_{2}$. Moreover, the difference in the photocatalytic activity of the saturated and monovacant Keggin unit functionalized titania was attributed to their different structures, which resulted in different electron-accepting abilities. Figure 5 shows the bonds between the HPA and the $\mathrm{TiO}_{2}$ support in the case of the "plenary" Keggin and the "lacunary" derivative.

Usually, the preparation of $\mathrm{TiO}_{2}$-supported HPAs gives rise to a composite for which there is an electrostatic acidbase interaction and/or hydrogen bonds between the HPA and the semiconductor. By using the lacunary HPA, the $\mathrm{K}_{7} \mathrm{PW}_{11} \mathrm{O}_{39} / \mathrm{TiO}_{2}$ composite shows a covalent bond between the terminal nucleophilic oxygen atoms of $\mathrm{K}_{7} \mathrm{PW}_{11} \mathrm{O}_{39}$ and the electrophilic titanium atoms in the Ti$\mathrm{OH}$ groups. Figure 5 shows the bonds between the HPA and $\mathrm{TiO}_{2}$. This material is particularly interesting because it opens the possibility to use functionalized HPAs that can be covalently linked to the support. The attractiveness of the covalent approach has been stressed by Proust, ${ }^{[64]}$ who indicated benefits as follows: (1) enhanced stability, which results in the ability of external variations in $\mathrm{pH}$ (in the stability range of the HPA), ionic strength, and leaching to be overcome; (2) enhanced control of the number and relative orientation of the components; and (3) better dispersion in a polymer or on a surface.

Lv et al. studied how the adsorption ability of the reactive orange 86 dye changes on the $\mathrm{TiO}_{2}$ Degussa P25 surface along with its photocatalytic degradation rate upon covering $\mathrm{TiO}_{2}$ with the HPAs. ${ }^{[65]}$ Owing to the presence of the HPA, the positive superficial charges of $\mathrm{TiO}_{2}$ were
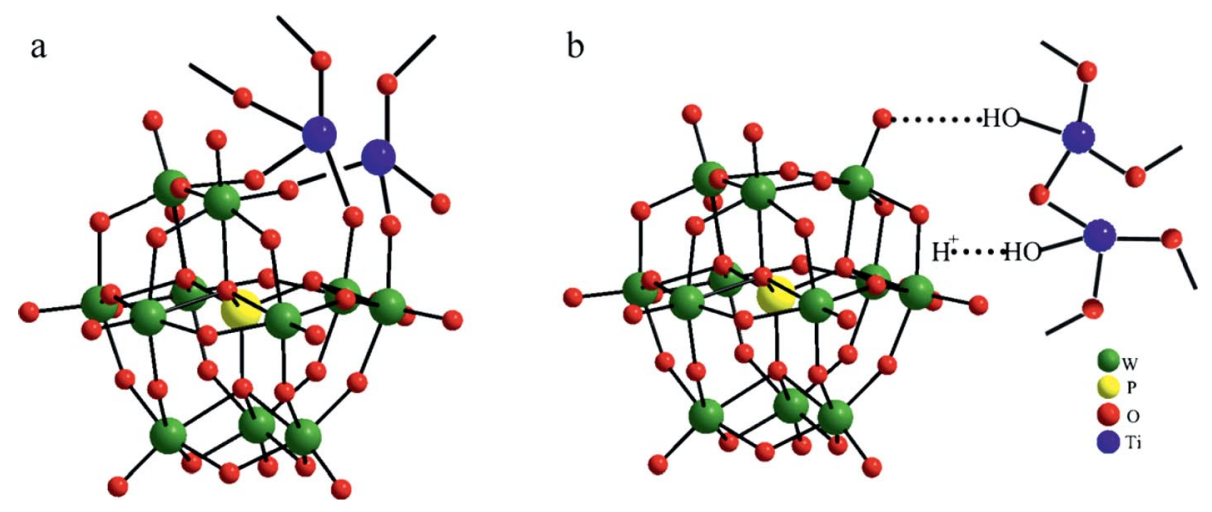

Figure 5. The proposed structures of the composites formed between (a) a "lacunary" $\mathrm{HPA}$ and $\mathrm{TiO}_{2}\left(\mathrm{~K}_{7} \mathrm{PW}_{11} \mathrm{O}_{39} / \mathrm{TiO}_{2}\right)$ and $(\mathrm{b})$ a "plenary" $\mathrm{HPA}$ and $\mathrm{TiO}_{2}\left(\mathrm{H}_{3} \mathrm{PW}_{12} \mathrm{O}_{40} / \mathrm{TiO}_{2}\right)$. Reprinted from ref. ${ }^{[63]}$ with permission from Elsevier. 
greatly reduced, and this resulted in a significant decrease in the adsorption of the anionic dye. Moreover, the presence of the HPA, replacing the surface hydroxy groups $\left(\mathrm{Ti}-\mathrm{OH}_{2}{ }^{+}\right.$ sites), favored the production of surface-bound $\mathrm{OH}$ radicals that are less reactive than free ${ }^{\circ} \mathrm{OH}$ radicals. These facts have a detrimental effect on the photocatalytic activity of the loaded sample with respect to that of bare $\mathrm{TiO}_{2}$. Visiblelight-responsive spherical particles composed of $\mathrm{TiO}_{2}$ and 20 or 30 wt.- $\% \mathrm{H}_{3} \mathrm{PW}_{12} \mathrm{O}_{40}$ were prepared through the solgel process and by using urea as the pore-forming agent. The malachite green oxalate dye bleaching reaction under $\mathrm{UV}$ and blue light irradiation in the aqueous phase were used as the model reactions. ${ }^{[6]}$ The prepared materials showed visible-light absorption owing to the presence of $\mathrm{WO}_{3}$, which resulted from the partial degradation of the HPA during the preparation drying step, and this also gave rise to lacunary $\left[\mathrm{PW}_{11} \mathrm{O}_{39}\right]^{7-}$ or dimeric $\left[\mathrm{P}_{2} \mathrm{~W}_{21} \mathrm{O}_{71}\right]^{6-}$ species. Dye solutions were efficiently bleached after $60 \mathrm{~min}$ with the most active composite, which contained $30 \mathrm{wt} .-\%$ of the HPA on $\mathrm{TiO}_{2}$. By using blue-light irradiation, this powder also revealed the highest photocatalytic bleaching. In that case, $\mathrm{WO}_{3}$ could be responsible for the observed photocatalytic activity. The same group treated the same $\mathrm{H}_{3} \mathrm{PW}_{12} \mathrm{O}_{40} /$ mesoporous titania composites at high temperatures. ${ }^{[67]}$ The Keggin structure was partially transformed upon thermal treatment of the samples up to $600{ }^{\circ} \mathrm{C}$. The HPA loading and the thermal treatment temperature influenced the activity of the photocatalyst. Biboum et al. synthesized the multi-cobalt- and multi-nickelsubstituted HPAs shown in Figure 6: ${ }^{[68]} \mathrm{K}_{10} \mathrm{Na}_{12}\left[\left(\mathrm{Co}_{3}\{\mathrm{~B}-\beta-\right.\right.$ $\left.\left.\left.\mathrm{SiW}_{9} \mathrm{O}_{33}(\mathrm{OH})\right\}\left\{\mathrm{B}-\beta-\mathrm{SiW}_{8} \mathrm{O}_{29}(\mathrm{OH})_{2}\right\}\right)_{2}\right] \cdot 49 \mathrm{H}_{2} \mathrm{O}(\mathbf{A}) ; \mathrm{K}_{20}[\{\mathrm{~B}-$ $\left.\beta-\mathrm{SiW}_{9} \mathrm{O}_{33}(\mathrm{OH})\left\{\mathrm{B}-\beta-\mathrm{SiW}_{8} \mathrm{O}_{29}(\mathrm{OH})_{2}\right\} \mathrm{Co}_{3}\left(\mathrm{H}_{2} \mathrm{O}\right)\right\}_{2} \mathrm{Co}-$ $\left.\left(\mathrm{H}_{2} \mathrm{O}\right)_{2}\right] \cdot 47 \mathrm{H}_{2} \mathrm{O}(\mathbf{B})$, and $\mathrm{Na}_{17}\left[\mathrm{Ni}_{6} \mathrm{As}_{3} \mathrm{~W}_{24} \mathrm{O}_{94}\left(\mathrm{H}_{2} \mathrm{O}\right)_{2}\right] \cdot$ $54 \mathrm{H}_{2} \mathrm{O}(\mathbf{C})$.
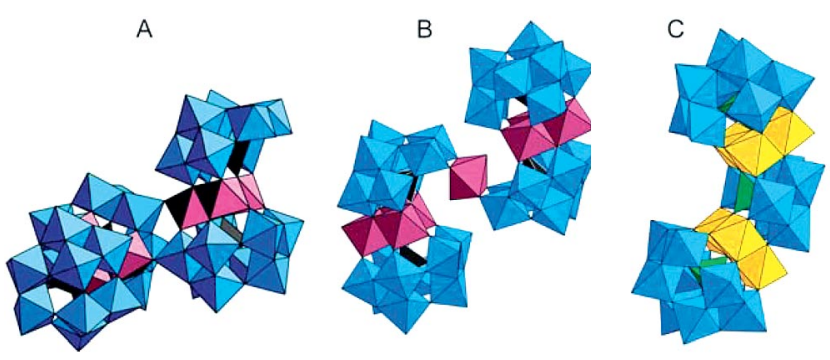

Figure 6. Polyanions of the salts synthesized: A, B, and C. $\mathrm{WO}_{6}$, $\mathrm{CoO}_{6}$, and $\mathrm{NiO}_{6}$ are represented as blue, purple, and yellow octahedra, respectively. $\mathrm{SiO}_{4}, \mathrm{AsO}_{4}$, and $\mathrm{PO}_{4}$ are represented as black, green, and orange tetrahedra, respectively. Adapted from ref. ${ }^{[68]}$ with permission of The Royal Society of Chemistry.

These HPAs absorb visible light as a result of the presence of the cobalt and nickel color centers, and this is in contrast to other HPAs that only absorb in the UV region. $\mathbf{A}$ and $\mathbf{B}$ formed two-electron and four-electron reduced species, respectively, whereas $\mathbf{C}$ formed a six-electron reduced species.

Their photocatalytic activities were tested for the degradation of the acid orange 7 dye in aqueous solution in the absence and in the presence of colloidal $\mathrm{TiO}_{2}$ and in the presence of 2-propanol or polyvinyl alcohol (PVA), used as electron donors, to study the photosensitivity of these HPAs in homogeneous media and in the presence of $\mathrm{TiO}_{2}$. The reduction of the HPA occurred along with the oxidation of 2-propanol in the homogeneous system, whereas 2-propanol oxidation decreased under visible light in the sequence A $>$ B $>>>\mathrm{H}_{3} \mathrm{PW}_{12} \mathrm{O}_{40}>$ C. The mechanism is shown below.

$\mathrm{HPA}+h v \rightarrow \mathrm{HPA}^{*}$

$\mathrm{HPA}^{*}+\mathrm{CH}_{3}-\mathrm{CHOH}-\mathrm{CH}_{3} \rightarrow \mathrm{HPA}^{2-}+\mathrm{CH}_{3}-\mathrm{CO}-\mathrm{CH}_{3}+2 \mathrm{H}^{+}(10)$

$\mathrm{HPA}^{2-}+\mathrm{CH}_{3}-\mathrm{CHOH}-\mathrm{CH}_{3} \rightarrow \mathrm{HPA}^{4-}+\mathrm{CH}_{3}-\mathrm{CO}-\mathrm{CH}_{3}+2 \mathrm{H}^{+}(11)$

The photoreduction kinetics with the use of $\mathrm{H}_{3} \mathrm{PW}_{12} \mathrm{O}_{40}$ are negligible, despite the more positive formal potential, relative to those with the use of $\mathrm{A}$ and $\mathrm{B}$. The higher photoreduction yield of these HPAs compared to the Keggin anions was mainly attributed to their extended absorption in the visible region and their ability to become multielectron photoreduced species. As far as dye degradation under visible-light irradiation (at $\mathrm{pH} 1$ in the presence of 2-propanol or PVA) is concerned, the photodegradation rate in the presence of the suspension containing $\mathbf{A}$ and $\mathrm{TiO}_{2}$ was three times higher than that in the presence of a homogeneous system containing $\mathbf{A}$. The photodegradation efficiency in the presence of colloidal $\mathrm{TiO}_{2}$ follows the order: $\mathbf{A}>\mathbf{B}$ $>\mathbf{C}>>>\mathrm{H}_{3} \mathrm{PW}_{12} \mathrm{O}_{40}$. The authors associated the role of $\mathrm{TiO}_{2}$ to the kinetics of surface-adsorbed species. For comparison purposes, dye bleaching was also carried out under UV irradiation $(\lambda>320 \mathrm{~nm})$ in suspension containing both the HPA and $\mathrm{TiO}_{2}$ in the presence of PVA. The order in the photocatalytic efficiency was the same. Under UV irradiation, the reaction was faster owing to the synergistic mechanism explained in Figure 4. In the presence of $\mathrm{O}_{2}$, the activity was reduced owing to competition between dye and oxygen for the reoxidation of the reduced HPA. Indeed, as reported by the authors, the decoloration process was due to reductive cleavage of the azo bond of acid orange 7 by the photoreduced HPA to yield sulfanilic acid and 1-amino2-naphthol.

Yoon and co-workers prepared composites containing $\mathrm{H}_{3} \mathrm{PW}_{12} \mathrm{O}_{40}$ and $\mathrm{Ag}^{+}-\mathrm{N}-\mathrm{TiO}_{2}$ nanochains. These materials are highly visible-light-sensitive photocatalysts for efficient two-color solar cells. ${ }^{[69]}$ The visible-light absorption of $\mathrm{Ag}^{+}-\mathrm{N}-\mathrm{TiO}_{2}$ became broader and stronger upon formation of composites with the HPA owing to charge transfer between the HPA and the $\mathrm{TiO}_{2}$ nanochains. Shi et al. ${ }^{[70]}$ prepared $\mathrm{Ce}-\mathrm{H}_{3} \mathrm{PMo}_{12} \mathrm{O}_{40} / \mathrm{TiO}_{2}$ and $\mathrm{La}-\mathrm{H}_{3} \mathrm{PW}_{12} \mathrm{O}_{40} / \mathrm{TiO}_{2}$ rare earth and HPA co-doped composite photocatalysts by a sol-gel method. These catalysts presented higher photocatalytic activity for the degradation of methylene blue dye than bare $\mathrm{TiO}_{2}$. The authors claimed the synergistic effect between the rare earth ions and the HPA along with the inhibition of the recombination of photogenerated electron-hole pairs, but they did not clarify the role of the socalled co-doping or that of the rare elements in the reaction mechanism. $\mathrm{TiO}_{2} / \mathrm{fly}$-ash cenosphere photocatalysts, modi- 
fied with $\mathrm{H}_{3} \mathrm{PW}_{12} \mathrm{O}_{40}$ or $\mathrm{H}_{3} \mathrm{SiW}_{12} \mathrm{O}_{40}$, were prepared through a sol-gel/solvothermal method. ${ }^{[71]}$ The composite materials shifted the absorption edge of the bare fly-ash $\mathrm{TiO}_{2}$ to the visible-light region. The photocatalytic mineralization of ciprofloxacin under visible-light irradiation was enhanced by using the sample containing the HPA, but no explanation was offered by the authors about this results. Feng et al. prepared $\mathrm{H}_{3} \mathrm{PW}_{12} \mathrm{O}_{40} / \mathrm{TiO}_{2}$ catalysts with different HPA loadings by an impregnation method. ${ }^{[72]}$ The visible-light activity of the samples was affected by both the HPA loading and the amount of lanthanum used as the doping element of $\mathrm{TiO}_{2}$. The prepared composites were used as photocatalysts for imidacloprid pesticide degradation and the 20 wt. $-0 \mathrm{H}_{3} \mathrm{PW}_{12} \mathrm{O}_{40} / 0.3$ wt. ${ }^{-} \% \mathrm{La}-\mathrm{TiO}_{2}$ sample showed the best photocatalytic activity by achieving 98\% pesticide conversion after $60 \mathrm{~min}$. The plenary Keggin cluster encapsulated in a titanium-exchanged HY (TiHY) zeolite was also used for the photocatalytic degradation of methyl orange. ${ }^{[73]}$ The photoreaction rate increased 20 times relative to the rate observed in the presence of the HPAencapsulated $\mathrm{HY}$ zeolite without $\mathrm{Ti}$ and 9 times relative to that observed for the TiHY zeolite without the HPA. The reaction rate increased four times by using the HPA-encapsulated TiHY zeolite relative to that obtained with the use of a home-prepared colloidal $\mathrm{TiO}_{2}$. The authors explained this fact by considering that the zeolite matrix provides a good dispersion of active titanium sites and free access of the dye molecules to these isolated sites, which help the photocatalytic activity. A NaY zeolite incorporating $\mathrm{TiO}_{2}$, $\mathrm{H}_{3} \mathrm{PMo}_{12} \mathrm{O}_{40}$, and $\mathrm{Co}^{\mathrm{II}}{ }^{[74]} \mathrm{Ni}^{\mathrm{iI}}$, and $\mathrm{Ru}^{\mathrm{III}[75]}$ were prepared for the photocatalytic degradation of methyl orange. The authors reported that the photoreduction of the dye by using the composite materials occurred through the reduced HPA species formed under solar irradiation, which transfers electrons to the transition metal through the assistance of the zeolite framework. The electron transfer was proposed to occur from the reduced HPA species to the Lewis acid sites of the zeolite and not directly to the transition metals that then provided electrons to methyl orange, which was photoreduced to hydrazine. Unfortunately, the authors did not report the fate of the aromatic rings of the dye or provide any information on substrate mineralization. A composite consisting of a zeolite ( $\mathrm{NaY}$ or Na-Mordenite) was successively impregnated with $\mathrm{TiO}_{2}, \mathrm{Co}^{\mathrm{II}}$, and $\mathrm{H}_{3} \mathrm{PW}_{12} \mathrm{O}_{40}$. This material was prepared for water splitting. ${ }^{[76]}$ Nitrate and chloride cobalt salts were used, and the $\mathrm{Co}\left(\mathrm{NO}_{3}\right)_{2}$ precursor gave rise to a photocatalyst that exhibited an improvement in the UV/Vis absorbance but caused an almost $30 \%$ lower $\mathrm{H}_{2}$ production rate in comparison to the material prepared by using $\mathrm{CoCl}_{2}$. The favorable shift towards visible light was attributed to the incorporation of nitrogen in the structure of the photocatalyst, and its lower hydrogen production rate was attributed to the competitive photoreduction reactions of the nitrate anions.

$\mathrm{ZnO}$ (band gap: $3.2 \mathrm{eV}$ ) is a photocatalytically active oxide that has been proposed as an alternative to $\mathrm{TiO}_{2}$. Unfortunately, its basic surface is not an ideal support to anchor strongly acidic HPAs; in fact, an acid-base reaction occurs on the surface, which gives rise to the total or partial decomposition of the cluster. ${ }^{[51]} \mathrm{ZrO}_{2}$ has been seldom used as a photocatalyst owing to its wide band gap energy of $5.0 \mathrm{eV}$ (ca. $250 \mathrm{~nm}$ ). ${ }^{[77]} \mathrm{H}_{3} \mathrm{PW}_{12} \mathrm{O}_{40} / \mathrm{ZrO}_{2}$ composites with loading levels of 5 to $20 \mathrm{wt} .-\%$ have been prepared by a wet impregnation method in ethanol medium. The authors reported that the interaction between $\mathrm{ZrO}_{2}$ and the HPA, in a manner analogous to that occurring between the HPA and $\mathrm{TiO}_{2}$, can be electrostatic or occur through hydrogen bonds. These interactions should avoid HPA leaching. The presence of the HPA on the $\mathrm{ZrO}_{2}$ surface gave rise to a redshift in the absorption spectrum of the material and hence to a narrowing of the band gap. ${ }^{[78]}$ Furthermore, the mesoporosity and homogeneous dispersion of the HPA on the oxide surface played important roles in improving the photocatalytic degradation of 4-nitrophenol and the methylene blue dye. The composites showed the best photocatalytic activity at HPA loadings not higher than $15 \mathrm{wt} .-\%$, and they were more active than both the bare HPA and $\mathrm{ZrO}_{2}$. The $\mathrm{ZrO}_{2}$-supported Ti-substituted Keggin-type $\mathrm{Li}_{5} \mathrm{PW}_{11} \mathrm{TiO}_{40} / \mathrm{ZrO}_{2}$ and $\mathrm{K}_{7} \mathrm{PW}_{10} \mathrm{Ti}_{2} \mathrm{O}_{40} / \mathrm{ZrO}_{2}$ polyoxometalates were prepared by incorporating the Keggin-type cluster into a $\mathrm{ZrO}_{2}$ matrix by sol-gel, which gave rise to a cluster chemically attached to the zirconia support. ${ }^{[79]}$ The photocatalytic activity of these heterogenized HPAs was tested for the degradation of the naphthol blue black dye, which was bleached and mineralized under UV illumination. The composites were more active than the homogeneous HPAs. The activity of the composites was attributed to the surface area of the composite and to electron transfer to the Keggin unit. $\mathrm{ZrO}_{2}$ precipitated by sol-gel in a solution containing $\mathrm{H}_{3} \mathrm{PW}_{12} \mathrm{O}_{40}$ was used for the partial oxidation of primary and secondary benzylic alcohols to the corresponding aldehydes and ketones. ${ }^{[00]}$ Aliphatic alcohols were also oxidized in good yields, but longer reaction times were required relative to the reactions of benzyl alcohols. The reaction mechanism proposed involves, in a first step, a direct $\mathrm{H}$-atom abstraction from the benzyl active $\mathrm{C}-\mathrm{H}$ bond of the alcohol by the photoexcited HPA rather than electron transfer.

$$
\begin{aligned}
& \mathrm{R}^{1} \mathrm{R}^{2} \mathrm{CHOH}+\mathrm{POM}^{*} \rightarrow \mathrm{R}^{1} \mathrm{R}^{2} \mathrm{C}-\mathrm{OH}+\mathrm{POM}^{-}+\mathrm{H}^{+} \\
& \mathrm{R}^{1} \mathrm{R}^{2} \mathrm{C} \cdot-\mathrm{OH}+\mathrm{POM}^{*} \rightarrow \mathrm{R}^{1} \mathrm{R}^{2} \mathrm{C}=\mathrm{O}+\mathrm{POM}^{-}+\mathrm{H}^{+}
\end{aligned}
$$

The $\mathrm{HPA} / \mathrm{ZrO}_{2}$ composite was more active than the bare HPA for partial alcohol oxidation. The HPA/ $\mathrm{ZrO}_{2}$ composite was activated by light absorption and it reacted with the alcohol to give the corresponding carbonyl compound. Reoxidation of the photoreduced HPA by dissolved $\mathrm{O}_{2}$ in the suspension completed the photocatalytic cycle. No information regarding the light source was given. The higher photocatalytic activity of $\mathrm{HPA} / \mathrm{ZrO}_{2}$ was explained analogously to that of the HPA/TiO ${ }_{2}$ materials (see Figure 4). The authors suggested a synergistic effect between $\mathrm{ZrO}_{2}$ and the photoactivated HPA. In another paper, $\mathrm{H}_{3} \mathrm{PMo}_{12} \mathrm{O}_{40} / \mathrm{ZrO}_{2}$ was prepared by incorporating the HPA into a $\mathrm{ZrO}_{2}$ matrix through sol-gel. In that way, $\mathrm{H}_{3} \mathrm{PMo}_{12} \mathrm{O}_{40}$ was chemically attached to the $\mathrm{ZrO}_{2}$ support and the primary Keggin structure remained intact. ${ }^{[81]}$ The 
photocatalytic activity was tested through degradation of the methylene blue, rhodamine $\mathrm{B}$, congo red, bromothymol blue, and alizarin dyes in aqueous solutions under UV light. Some of the characterization data reported in this paper are exactly the same as those reported in ref. ${ }^{[80]}$; however, in this case, the authors used a high-pressure mercury lamp as the light source. The HPA/ZrO $\mathrm{ZO}_{2}$ nanocomposite showed higher photocatalytic activity than both the bare HPA and $\mathrm{ZrO}_{2}$.

$\mathrm{Ta}_{2} \mathrm{O}_{5}$ is not a very popular material in photocatalysis. It has a band gap energy of $3.9 \mathrm{eV}$. It has shown some photoactivity under UV irradiation ${ }^{[82]}$ and under visible light only if doped with $\mathrm{N}^{\left[{ }^{[83]}\right.}$ Guo and co-workers prepared HPA/ $\mathrm{Ta}_{2} \mathrm{O}_{5}$ composites by a sol-gel/hydrothermal method in the presence of a pluronic surfactant, which gave rise to a high surface area 3D interconnected framework, ${ }^{[84]}$ in a manner analogous to that observed in the preparation of $\mathrm{TiO}_{2} \cdot{ }^{[60]}$ They deposited $\mathrm{H}_{3} \mathrm{PW}_{12} \mathrm{O}_{40}$ and $\mathrm{H}_{6} \mathrm{P}_{2} \mathrm{~W}_{18} \mathrm{O}_{62}$ on $\mathrm{Ta}_{2} \mathrm{O}_{5}$ with loading levels of 5.6-15.3 wt.- $\%$ and used these composites to decompose and mineralize salicylic acid and rhodamine $\mathrm{B}$ under visible-light excitation. ${ }^{[85]}$ Analogous to that reported for the HPA/TiO ${ }_{2}$ composite ${ }^{[60]}$ and owing to the similar electronegativity and ionic radius of $\mathrm{Ta}^{5+}$ and $\mathrm{W}^{6+}$, the authors claimed the existence of an electrostatic interaction between the terminal $\mathrm{W}=\mathrm{O}$ groups of the Keggin cluster and the $\mathrm{Ta}-\mathrm{OH}_{2}{ }^{+}$groups (formed by an acidbase reaction between the surface of the oxide and $\mathrm{H}_{3} \mathrm{PW}_{12} \mathrm{O}_{40}$ ) on the surface of the oxide, that is, the formation of $\left(\mathrm{TaOH}_{2}\right)^{+}\left[\mathrm{H}_{2} \mathrm{PW}_{12} \mathrm{O}_{40}\right]^{-}$or $\left(\mathrm{TaOH}_{2}\right)^{+}-$ $\left[\mathrm{H}_{5} \mathrm{P}_{2} \mathrm{~W}_{18} \mathrm{O}_{62}\right]^{-}$. The absorption threshold onset of these $\mathrm{HPA} / \mathrm{Ta}_{2} \mathrm{O}_{5}$ composites was extended to the visible region $(420 \mathrm{~nm})$ and resulted in an enhancement in the photocatalytic activity of these composites relative to that of both the bare HPA units and $\mathrm{Ta}_{2} \mathrm{O}_{5}$. The authors attributed the increase in the photocatalytic activity to the physicochemical features of the HPA/ $/ \mathrm{Ta}_{2} \mathrm{O}_{5}$ composites (porous structure, small particle size, homogeneous dispersion) in the same way as the analogous $\mathrm{HPA} / \mathrm{TiO}_{2}$ system prepared by the same group. ${ }^{[60]}$ In any case, the authors claimed the synergism between the HPA and the $\mathrm{Ta}_{2} \mathrm{O}_{5}$ semiconductor oxide in the terms explained in Figure 4 for the HPA/TiO composites.

\section{HPA-Based Materials with HPA Associated to Inorganic, Organic, or Organometallic Moieties}

HPA-based inorganic-organic hybrids have drawn much attention in various areas. A three component system consisting of $\mathrm{Au} / \mathrm{HPA} /$ carbon nanotubes (CNTs) with visiblelight photocatalytic activity was obtained upon using Keggin structures as both reducing and bridging molecules between $\mathrm{Au}$ metallic nanoparticles (NPs) and the CNTs. ${ }^{[86]} \mathrm{A}$ thin HPA layer (ca. $2 \mathrm{~nm}$ thick) was deposited around the gold nanoparticle supports that were on the surfaces of the CNTs. The Au/HPA/CNT composite was more active for the photocatalytic degradation of rhodamine B under visible light than the one- or two-component photocatalyst.
The authors justified the enhanced photocatalytic activity by considering a synergistic effect between the three components. Indeed, the visible-light excitation of the surface plasmon resonance of the $\mathrm{Au}$ nanoparticles induces electron transfer from Au to the HPA. In this way, the electron-deficient $\mathrm{Au}$ nanoparticles can oxidize the organic compounds. In contrast, electron transfer from the reduced HPA to the CNTs can decrease electron-hole recombination. Finally, the trapped electrons on the CNTs can react with $\mathrm{O}_{2}$ (see Figure 7).

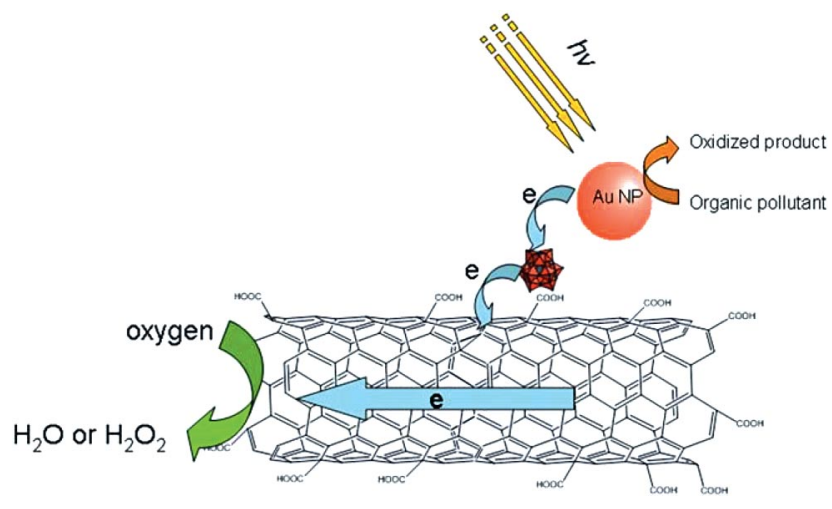

Figure 7. Photocatalytic mechanism of Au nanoparticles/HPA/ CNT three-component nanohybrid. Reproduced from ref. ${ }^{[86]}$ with permission of The Royal Society of Chemistry.

The same group prepared molecular self-assembled CdS quantum dots $-\mathrm{H}_{3} \mathrm{PW}_{12} \mathrm{O}_{40}-\mathrm{Au}$ nanoparticles nanohybrids. This nanohybrid three-component material is analogous to that discussed above; in fact, the authors replaced the CNTs with CdS quantum dots (QDs), but the role played by $\mathrm{CdS}$ was different from that played by the CNTs. This composite showed photocatalytic activity both in the photoproduction of $\mathrm{H}_{2}$ and in the degradation of rhodamine $\mathrm{B}$ and methyl orange under visible irradiation. ${ }^{[87]}$ It was synthesized by the molecular self-assembly of amine-modified CdS and HPA-wrapped Au nanoparticles. In this way, the Keggin cluster coupled with CdS and the Au nanoparticles. The photocatalytic activity of bare CdS, HPA, and Au was negligible; on the contrary, the presence of the three components in the nanohybrid material increased the photocatalytic performance. Moreover, the activity increased by increasing the Au loading at least up to $6 \% \mathrm{w} / \mathrm{w}$, which was the maximum quantity of $\mathrm{Au}$ used. The authors also reported that the two-component $\mathrm{CdS}-\mathrm{Au}$ hybrid with the same Au loading showed lower activity with respect to the composite also containing the HPA, which indicated that the HPA played a fundamental role because it promoted the separation of photoproduced electron-hole pairs on the CdS quantum dots (see Figure 8).

Kim et al. reported the self-assembly of positively charged amine-modified CdS quantum dots and negatively charged Keggin HPA nanoclusters to produce CdS-HPA nanohybrids. ${ }^{[88]}$ This material exhibited a higher activity for $\mathrm{H}_{2}$ production than bare CdS. The authors attributed the improvement in photocatalytic activity to an increase in the lifetime of the excited electrons as a result of electron trans- 


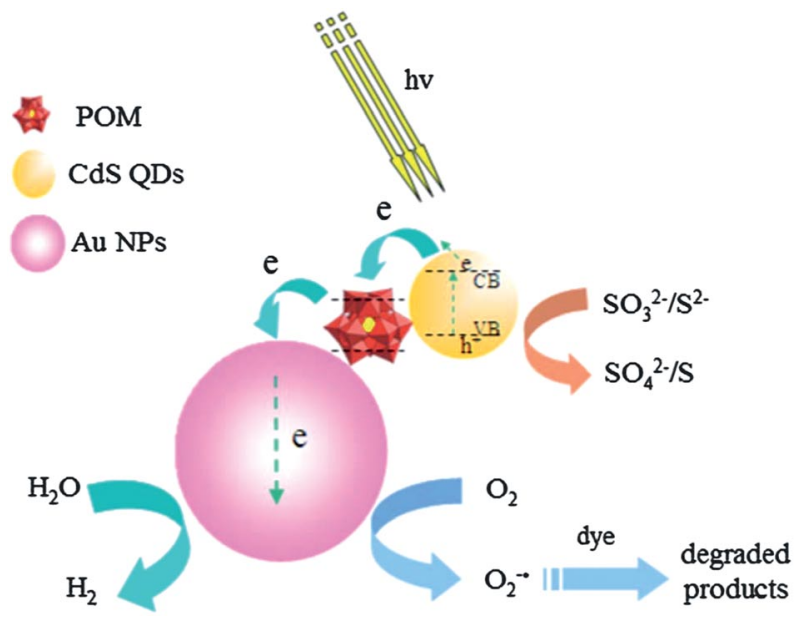

Figure 8. The photocatalytic mechanism of the CdS-Au-HPA nanohybrid. Reproduced from ref. ${ }^{[87]}$ with permission of The Royal Society of Chemistry.

fer between CdS and the HPA, as evidenced by photoluminescence experiments. The photocatalytic activity of the asprepared nanohybrid was further improved by the deposition of a Pt cocatalyst.

The idea to prepare hybrid materials by coupling oppositely charged compounds in which one of them was a heteropolyacid was followed by other authors. For instance, $\mathrm{Cao}$ and co-workers adopted some strategies to obtain HPA-based inorganic-organic composites for the photocatalytic degradation of organic molecules. They prepared a composite consisting of a sterically big metal complex cation, the hexacopper phosphate $\left[\mathrm{Cu}_{6}\left(\mathrm{PO}_{4}\right)_{2}\left(\mathrm{H}_{2} \mathrm{O}\right)_{4}\right.$ (phen $\left.)_{6}\right]^{6+}$, and the Wells-Dawson polyoxoanion $\left[\mathrm{P}_{2} \mathrm{~W}_{18} \mathrm{O}_{62}\right]^{6-}$. Charge transfer between the metal complex and the polyanion gave rise to an absorption at $690 \mathrm{~nm}$. This material was used for the photocatalytic degradation of the methyl orange dye in the presence of $\mathrm{H}_{2} \mathrm{O}_{2} \cdot{ }^{[89]}$ The hexacopper phosphate cluster acted as a visible-light sensitizer and delivered electrons into the LUMO of the WellsDawson HPA. The electrons were trapped by adsorbed $\mathrm{H}_{2} \mathrm{O}_{2}$ to yield $\mathrm{OH}$ radicals that oxidized the dye. The same group used another organic cation, that is, the macrocyclic cucurbituril, to form a water-insoluble composite with the Keggin-type $\left[\mathrm{SiW}_{12} \mathrm{O}_{40}\right]^{3-}$ anion (see Figure 9). ${ }^{[90]}$
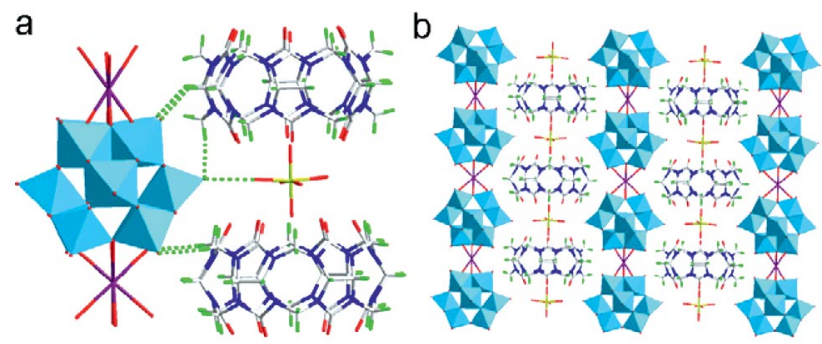

Figure 9. (a) Hydrogen bond interactions between neighboring Keggin HPA [ $\left.\mathrm{SiW}_{12} \mathrm{O}_{40}\right]^{4}$ and cucurbituril units to form the composite (b). Reprinted from ref. ${ }^{[90]}$ with permission from Elsevier.

In this case also, the photocatalytic test reaction was the degradation of methyl orange under visible-light irradia- tion. In the photodegradation process, the macrocyclic organic chain acted as a sensitizer under visible light, whereas the HPA chain acted as an electron acceptor. Figure 9 shows the interaction of the cucurbituril with the HPA (Figure 9 , a) and the packing structure of the composite (Figure 9, b). Cao et al. also prepared two water-insoluble supramolecular assemblies by using cucurbituril derivatives and Wells-Dawson HPAs by a hydrothermal process. ${ }^{[91]}$ The composites $\left[\mathrm{K}_{2}\left(\mathrm{H}_{2} \mathrm{O}\right)_{2} \mathrm{Na}_{2}\left(\mathrm{H}_{2} \mathrm{O}\right)_{2} \mathrm{Na}_{2}\left(\mathrm{H}_{2} \mathrm{O}\right)_{6}\right]$ $\left.\left(\mathrm{P}_{2} \mathrm{~W}_{18} \mathrm{O}_{62}\right)\left(\mathrm{Me}_{10} \mathrm{Q}_{5}\right)_{2}\right\} \approx 77 \mathrm{H}_{2} \mathrm{O}$ (D) and $\left\{\left[\mathrm{Rb}_{2}\left(\mathrm{H}_{2} \mathrm{O}\right)_{2} \mathrm{Na}_{2^{-}}\right.\right.$ $\left.\left.\left(\mathrm{H}_{2} \mathrm{O}\right)_{2} \mathrm{Na}_{2}\left(\mathrm{H}_{2} \mathrm{O}\right)_{4}\right]\left(\mathrm{P}_{2} \mathrm{~W}_{18} \mathrm{O}_{62}\right)\left(\mathrm{Me}_{10} \mathrm{Q}_{5}\right)_{2}\right\} \approx 7 \mathrm{H}_{2} \mathrm{O} \quad(\mathbf{E})$, in which $\left(\mathrm{Me}_{10} \mathrm{Q}_{5}\right)$ represents the cucurbituril derivative species (see Figure 10, b), exhibited a similar network. Indeed, in $\mathbf{E}$ there is a substitution of $\mathrm{K}^{+}$with $\mathrm{Rb}^{+}$and a different number of coordinated/uncoordinated water molecules. Figure 10 represents the organic-inorganic composites.

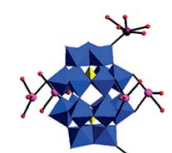

(a) $\%$

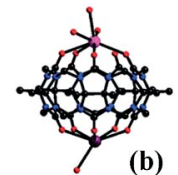

(b)

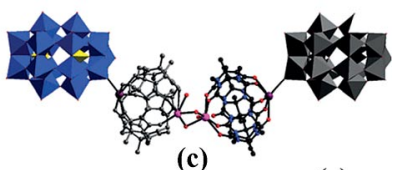

(c)
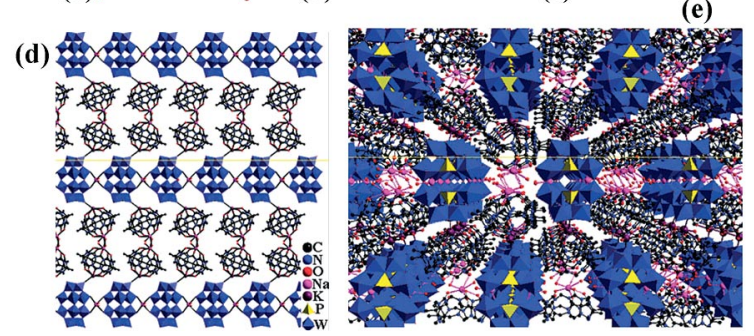

Figure 10. Scheme of the HPA (a) and cucurbituril (b) basic building blocks and the linkage between them (c), along with the 2D (d) and 3D (e) matrix of compound D. Reproduced from ref. ${ }^{[91]}$ with permission of The Royal Society of Chemistry.

The authors described the activity of composite $\mathbf{D}$ and inferred that the activity of composite $\mathbf{E}$ should be similar. Composite $\mathbf{D}$ was active for the photocatalytic bleaching and mineralization of both methyl orange and rhodamine B under visible-light irradiation. The material was recycled five times and maintained its activity. The hybrid systems absorbed in the visible region; in fact, the diffuse reflectance spectrum of composite $\mathbf{D}$ exhibited a broad band centered at ca. $890 \mathrm{~nm}$, which was ascribed to an intense charge transfer between $\left(\mathrm{Me}_{10} \mathrm{Q}_{5}\right)$ and $\left\{\mathrm{P}_{2} \mathrm{~W}_{18} \mathrm{O}_{62}\right\}^{6-}$. The authors proposed the classical mechanism in which the HPA was firstly activated by visible light to photo-oxidize organic substrates by the generation of free radicals that attacked the dye molecule. The reduced HPA was reoxidized by $\mathrm{O}_{2}$. The same group also prepared a water-insoluble composite constituted by the Keggin HPA and thionine (TH) with a simple precipitation method to obtain $(\mathrm{TH})_{3} \mathrm{PW}_{12} \mathrm{O}_{40}$ powders with specific surface area of ca. $20 \mathrm{~m}^{2} \mathrm{~g}^{-1}$. Rhodamine $\mathrm{B}$ was bleached and mineralized under visible light $(\lambda$ $>420 \mathrm{~nm}$ ). TH acted as a sensitizer and extended the spectrum of $\mathrm{H}_{3} \mathrm{PW}_{12} \mathrm{O}_{40}$ into the visible region. ${ }^{[92]} \mathrm{TH}$ was excited by visible light, and subsequently, it could inject electrons into the LUMO of the HPA. In this way, $\mathrm{O}_{2}$ trapped an electron to generate oxidant radicals that were able to 
mineralize the rhodamine B molecules. The mechanism proposed for the sensitization is schematized in Figure 11. In this paper, the authors did not explain the fate of the oxidized TH $\left(\mathrm{TH}^{*+}\right)$; consequently, from the reported mechanism it seems that TH can also be degraded during the photocatalytic tests and this should result in the deactivation of the catalyst, which was not observed, at least after five reaction cycles.

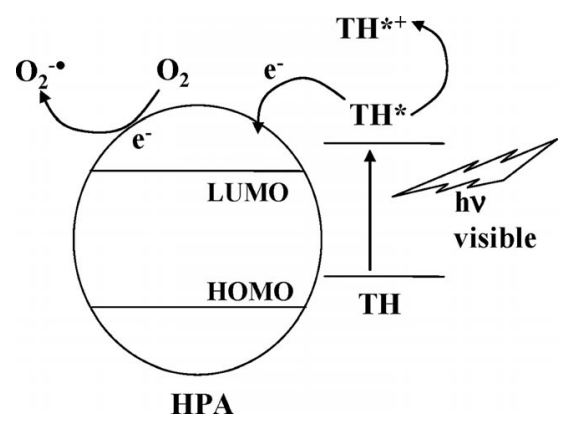

Figure 11. Proposed mechanism for HPA sensitization by thionine. Adapted from ref. ${ }^{[92]}$ with permission from Elsevier.

Another type of HPA-based composite material was prepared by Bonchio et al. They obtained an organic-sensitized HPA heterogeneous photocatalyst by using a modified fullerene as the sensitizer. ${ }^{[93]}$ They followed two strategies: the covalent functionalization of lacunary decatungstosilicate with organosilylfulleropyrrolidines and the electrostatic interaction between a cationic sensitizer and the HPA. The Keggin-based lacunary HPA $\left(\left[\mathrm{SiW}_{10} \mathrm{O}_{36}\right]^{8-}\right)$ functionalized with tris(alkoxysilane)-C60-fulleropyrrolidines (see Figure 12) showed good photocatalytic activity for the photooxidation of phenol and L-methionine methyl ester to the corresponding sulfoxide. The reactions were carried out in aqueous solution under irradiation $(\lambda>375 \mathrm{~nm})$. Phenol was partially oxidized to benzoquinone with ca. $90 \%$ conversion. The solid photocatalyst was recycled three times without losing its activity. The presence of fullerene was essential for the photocatalytic activity; in fact, photocatalysts functionalized with $\mathrm{Si}\left(\mathrm{CH}_{2}\right)_{x} \mathrm{R}$ groups $\left(\mathrm{R}=\mathrm{Me}, \mathrm{NH}_{2}\right.$, $\mathrm{Ph}$ ) were inactive. The type of bonding between the fuller-

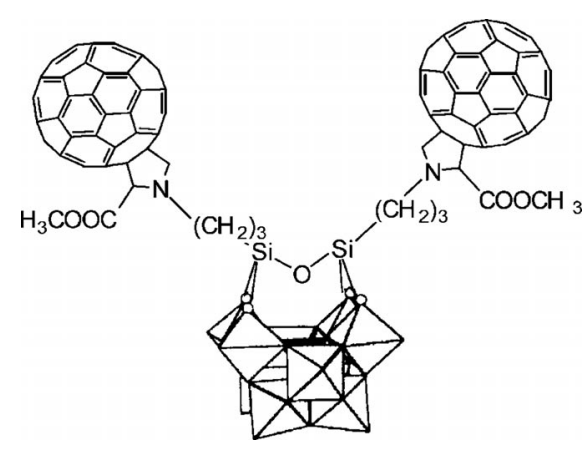

Figure 12. Structure of the lacunary HPA functionalized with the fullerene derivative. Adapted with permission from ref. ${ }^{[93]}$ Copyright 2004 Wiley-VCH Verlag GmbH \& Co. KGaA. ene and the HPA had a huge effect on the stability of the system and was used to modify the photocatalytic performance.

Zhou et al. prepared an HPA-based plasmonic visiblelight $\mathrm{Ag} / \mathrm{Ag}_{x} \mathrm{H}_{4-x} \mathrm{SiW}_{12} \mathrm{O}_{40}(\mathrm{Ag} / \mathrm{AgHSiW})$ photocatalyst. ${ }^{[94]}$ The composite nanoparticles, possessing more $\mathrm{OH}$ surface groups than $\mathrm{TiO}_{2}$ Degussa P25, showed a strong and broad absorption in the visible region and a weak plasmonic emission. The Ag/AgHSiW material showed higher photocatalytic activity for the decomposition of methylene blue dye under visible-light irradiation than bare $\mathrm{Ag}$ nanoparticles, $\mathrm{H}_{4} \mathrm{SiW}_{12} \mathrm{O}_{40}$, and $\mathrm{Ag}_{4} \mathrm{SiW}_{12} \mathrm{O}_{40}$. The composite activity was attributed to the synergistic effect of the photoexcited HPA (AgHSiW) and the plasmon-excited $\mathrm{Ag}$ nanoparticles. The HPA showed redox ability and photocatalytic activity, whereas Ag could effectively accelerate the separation of the electrons and holes.

As already reported, the association of HPAs to inorganic, organic, or organometallic moieties was developed as a result of the limitations of the HPA-supported materials, including (1) low homogeneous HPA loading, which gives rise to non-uniform dispersion of the active sites, (2) HPA leaching, and (3) deactivation of acid sites by water or polar molecules. In this context, immobilization inside a suitable solid host matrix could be considered a convenient approach to develop a (photo)catalyst. An optimum host should possess the following features: (1) Suitable cavities with adequate size and shape to encapsulate the HPA guest molecule, which would allow a homogeneous HPA dispersion inside the solid. (2) Appropriate openings for the diffusion of reactants and products. (3) Mild and simple preparation conditions of the composite. (4) Stability. Metal-organic frameworks (MOFs) that have recently emerged as a particular class of functional solid-state materials have been identified as adequate candidates. ${ }^{[95]}$ HPAs decorating the MOFs surface were reported as good heterogeneous catalysts, because they exhibited satisfactory immobilization along with an improvement in other catalytic properties. ${ }^{[96]}$ However, the introduction of HPAs into the MOFs to form PMOFs ( $\mathrm{P}=\mathrm{POM}$, polyoxometalate) was found to be one of the most promising strategies to optimize the performance of the HPA clusters. ${ }^{[97]}$ In this context, Guo et al. prepared, by using the hydrothermal method currently used in the preparation of PMOFs, a supramolecular compound with the formula $\left[\left(\mathrm{H}_{2} \text { toym }\right)_{2}\left(\mathrm{SiW}_{12} \mathrm{O}_{40}\right)\right] \cdot 6 \mathrm{H}_{2} \mathrm{O}$, in which "toym" is a multidentate $\mathrm{O}$-donor ligand, that is, $(2,4,6-$ tris[1-(4-oxidroxypyridinium)ylmethyl]mesitylene). ${ }^{[98]}$ The solid network was templated by the HPA. The "host" supramolecular network, with large pores, is composed of the partly protonated O-donor ligands, whereas the HPA "guest" is located in the pores and dispersed between two organic layers in the complexes. The compound exhibited photocatalytic activity for methylene blue bleaching under UV-light irradiation. The optical absorbance allowed the band gap of the solid to be calculated $(2.65 \mathrm{eV})$. No explanation of the mechanism of the photocatalytic reaction was given by the authors. Liu et al. prepared four PMOFs by using bis(triazole) $\mathrm{N}$-donor ligands. They used the 
$\left[\mathrm{Mo}_{6} \mathrm{O}_{18}\left(\mathrm{O}_{3} \mathrm{AsPh}\right)_{2}\right]^{4-}$ HPA and copper(I)-organic fragments containing the triazole ligands. ${ }^{[99]}$ The structures possessed band gap between 2.7 and $1.9 \mathrm{eV}$, and they were used for the bleaching of methylene blue by irradiating with a $500 \mathrm{~W}$ Xe lamp. The authors discovered that the presence of $\mathrm{O}_{2}$ was essential for the photocatalytic process, but no additional explanation of the mechanism was given. The layered double hydroxide (LDH) architecture was also used to design 3D frameworks with large channels hosting the plenary Keggin HPA. ${ }^{[100]}$ The material exhibited a 3D Ce ${ }^{\mathrm{III}}$ hydrotalcite-like structure constructed from 2D cationic $\left[\left\{\mathrm{Ce}\left(\mathrm{H}_{2} \mathrm{O}\right)_{5}\right\}_{2}\left\{\mathrm{Ce}(\mathrm{pdc})_{2}\left(\mathrm{H}_{2} \mathrm{O}\right)_{4}\right\}\left\{\mathrm{Ce}(\mathrm{pdc})_{3}\right\}\right]^{2+}$ layers, in which pdc $=$ pyridine-2,6-dicarboxylate, pillared by $\left[\mathrm{PW}_{12} \mathrm{O}_{40}\right]^{3-}$ anions (see Figure 13).

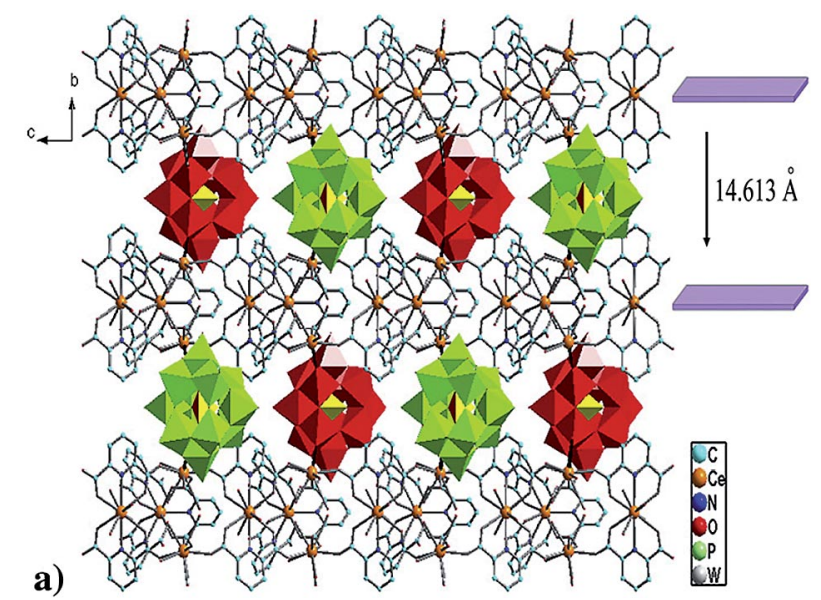

Figure 13. Pillared layer architecture containing the Keggin HPA. Reprinted ref. ${ }^{[100]}$ with permission from Elsevier.

This material was active for photocatalytic $\mathrm{H}_{2}$ evolution in methanol aqueous solution under UV irradiation. Further efforts should be addressed to understand the mechanism of this reaction by using the HPA-LDH material.

Biboum et al. synthesized and assembled polyionic liquids (PILs) with a HPA to form water-insoluble nanomaterials. ${ }^{[101]}$ The macrocyclic $\left[\mathrm{H}_{7} \mathrm{P}_{8} \mathrm{~W}_{48} \mathrm{O}_{184}\right]^{33-}$ HPA (see Figure 14) synthetized by the authors was stable in aqueous media, underwent fast and chemically reversible eight-electron reduction processes, and interacted with different imidazolium-based PILs to form a water-insoluble heterogeneous photocatalyst. This photocatalyst was able to bleach the acid orange 7 dye also in the absence of $\mathrm{O}_{2}$ and under visible-light irradiation $(\lambda>400 \mathrm{~nm})$. On the contrary, the bare HPA and PIL showed negligible activity, which indicated that a synergistic effect occurred upon coupling the two species.

Moreover, the authors claimed that with their photocatalyst the complete mineralization of acid orange 7 was also achieved, although they did not report any strong experimental evidence to prove this; indeed, they followed only the disappearance of the characteristic bands of acid orange 7 in the UV/Vis spectrum.

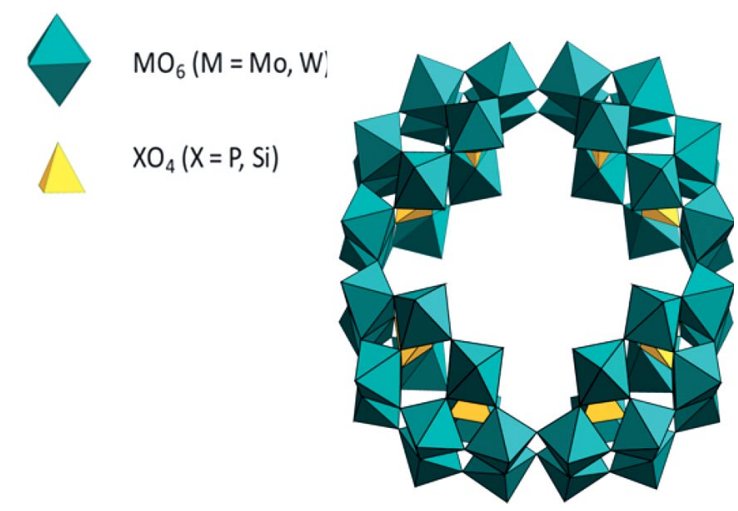

Figure 14. The heteropolyacid prepared by Biboum et al., which was used as a homogeneous photocatalyst in solution and as a heterogeneous catalyst upon bonding to PILs. Adapted from ref. ${ }^{[101]}$ with permission of The Royal Society of Chemistry.

Recently, porous coordination polymers (PCPs) were used as hosts to guest HPAs. Fu et al. reported a kind of PCP/HPA host-guest compound constituted by $\left[\mathrm{Cu}_{2}{ }_{2} \mathrm{Cu}_{3}{ }_{3}(\mathrm{OH})_{4}\left(\mathrm{H}_{2} \mathrm{O}\right)_{2}(\mathrm{TPT})_{4}\right]\left[\mathrm{PW}_{12} \mathrm{O}_{40}\right]$, in which TPT = tris(4-pyridyl)triazine. In this supramolecular compound, the Keggin anion is located at the center of a large cationic ring containing TPT and $\mathrm{Cu}$ cations. ${ }^{[102]}$ According to the authors, this metal-organic host framework strengthened the photocatalytic ability of the HPA, which was able to bleach methyl orange under UV irradiation. The bleaching rate was very low with the use of this supramolecular compound, but it dramatically increased in the presence of $\mathrm{H}_{2} \mathrm{O}_{2}$. Notably, the runs were carried out at almost neutral $\mathrm{pH}$, which is different from that reported by Cao, who carried out photocatalytic tests with the same model molecule and the heterogenized Keggin HPA at highly acidic $\mathrm{pH}$ values. ${ }^{[92]}$

\section{Conclusions}

The photocatalytic activity of heteropoly compounds in a homogeneous regime has been extensively reported along with the use of supported HPAs in thermal catalysis for acidic and redox processes. The nature of the HPAs as highly soluble compounds in polar solvents hinders their use as heterogeneous photocatalysts. Consequently, appropriate heterogenization has been reported by many researches so that HPAs can be used in heterogeneous reaction media, in particular to carry out photocatalytic degradations of several pollutants. The preparation of supported HPAs both onto inactive and photocatalytically active oxides has been carried out by several methods, which has given rise to materials in which the nature of the HPA was maintained and in which the bond between the support and the HPA was mainly electrostatic. This interaction seems to be strong enough to avoid significant leaching of the HPA. Nevertheless, a covalent bond between the HPA and the oxide surface is more effective in preventing leaching, and this bond has been formed by using "lacunary" and functionalized HPAs linked to supports that could themselves 
be functionalized. The HPAs act as photocatalysts in a manner similar to that observed in the homogeneous regime, but the use of photocatalytically active oxides as supports appears preferable to the use of non-photocatalytically active supports. Indeed, the improvement in the photocatalytic activity found by using HPA-based composites was related in the first case to electron transfer from the excited HPA to $\mathrm{O}_{2}$ to form the final oxidant species, that is, hydroxy radicals. This electron transfer can occur directly from the HPA to the $\mathrm{O}_{2}$ or alternatively through the conduction band of the photoexcited oxides. Also, carbon nanotubes and metal nanoparticles have been used instead of oxides. Recently, an alternative approach was explored by means of host-guest materials in which the guest HPA was incorporated into inorganic and organic supramolecular hosts. The reason for the improvement in the photocatalytic activity of the HPAs inside the host systems is still unclear. Home-tailored HPAs, different from the morestudied Keggin and Wells-Dawson structures, represent a novelty in this field, particularly if they are "heterogenized" by using polyionic liquids. Nevertheless, an effort to clarify the mechanism of the reaction is necessary. The degradation of dyes as model molecules is often reported to test the photocatalytic activity of heterogenized HPAs. The use of alternative and more challenging molecules is a must to fully understand the mechanistic aspects of the photocatalytic heterogeneous process.

\section{Acknowledgment}

The authors thank the MIUR for economical support (PON01_ 02257).

[1] A. Fujishima, K. Honda, Nature 1972, 238, 37-38.

[2] M. Schiavello (Ed.), Photocatalysis and Environment: Trends and Applications, Kluwer, Dordrecht, The Netherlands, 1988.

[3] H. Chen, C. E. Nanayakkara, V. H. Grassian, Chem. Rev. 2012, 112, 5919-5948.

[4] A. Kubacka, M. Fernández-García, G. Colón, Chem. Rev. 2012, 112, 1555-1614.

[5] a) L. Palmisano, V. Augugliaro, M. Bellardita, A. Di Paola, E. García-López, V. Loddo, G. Marcì, G. Palmisano, S. Yurdakal, ChemSusChem 2011, 4, 1431-1438; b) G. Palmisano, E. I. García-López, G. Marcì, V. Loddo, S. Yurdakal, V. Augugliaro, L. Palmisano, Chem. Commun. 2010, 46, 7074-7089; c) Y. Shiraishi, T. Hirai, J. Photochem. Photobiol. C: Photochem. Rev. 2008, 9, 157-170.

[6] A. Di Paola, E. I. García-López, G. Marcì, L. Palmisano, J. Hazard. Mater. 2012, 211-212, 3-29.

[7] G. Marcì, M. Addamo, V. Augugliaro, S. Coluccia, E. I. García-López, V. Loddo, G. Martra, L. Palmisano, M. Schiavello, J. Photochem. Photobiol. A: Chem. 2003, 160, 105-114.

[8] S. G. Kumar, L. G. Devi, J. Phys. Chem. A 2011, 115, 1321113241.

[9] M. T. Pope, Heteropoly and Isopoly Oxometalates, Springer, Berlin, 1983.

[10] D. E. Katsoulis, Chem. Rev. 1998, 98, 359-387.

[11] D. Long, E. Burkholder, L. Cronin, Chem. Soc. Rev. 2007, 36, 105-121.

[12] a) A. Maldotti, A. Molinari, F. Biggi, J. Catal. 2008, 253, 312317; b) A. Molinari, R. Amadelli, A. Mazzacani, G. Sartori, A. Maldotti, Langmuir 2002, 18, 5400-5405; c) C. Tanielian,
Coord. Chem. Rev. 1998, 178-180, 1165-1181; d) M. D. Tzirakis, I. N. Lykakis, G. D. Panagiotou, K. Bourikas, A. Lycourghiotis, C. Kordoulis, M. Orfanopoulos, J. Catal. 2007, 252, 178-189; e) I. N. Likakis, E. Evgenidou, M. Orfanopoulos, Curr. Org. Chem. 2012, 16, 2400-2414.

[13] M. T. Pope, A. Müller, Angew. Chem. 1991, 103, 56-70; Angew. Chem. Int. Ed. Engl. 1991, 30, $34-48$.

[14] a) N. Mizuno, M. Misono, Chem. Rev. 1998, 98, 199-217; b) T. Okuhara, N. Mizuno, M. Misono, Adv. Catal. 1996, 41, 113252; c) M. Misono, Chem. Commun. 2001, 1141-1152.

[15] L. E. Briand, G. T. Baronetti, H. J. Thomas, Appl. Catal. A 2003, 256, 37-50.

[16] I. K. Song, M. S. Kaba, M. A. Barteau, Langmuir 2002, 18, $2358-2362$.

[17] A. Micek-Ilnicka, J. Mol. Catal. A 2009, 308, 1-14.

[18] I. V. Kozhevnikov, Catalysis for Fine Chemical Synthesis, vol. 2: Catalysis by Polyoxometalates, Wiley, Chichester, UK, 2002.

[19] I. V. Kozhevnikov, Chem. Rev. 1998, 98, 171-198.

[20] a) Polyoxometalates in catalysis (special issue): C. L. Hill (Ed.), J. Mol. Catal. A 1996, 114, 1-359; b) polyoxometalates (special issue): C. L. Hill (Ed.), Chem. Rev. 1998, 98, 1-387; c) heteropolyacids (special issue): I. Kiricsi, Á. Molnár (Eds.), Appl. Catal. A 2003, 256, 1-328; d) Y. Guo, C. Hu, J. Mol. Catal. A 2007, 262, 136-148; e) R. Sivakumar, J. Thomas, M. Yoon, $J$. Photochem. Photobiol. C: Photochem. Rev. 2012, 13, 277-298.

[21] L. R. Pizzio, C. V. Cáceres, M. N. Blanco, Appl. Catal. A 1998, 167, 283-294.

[22] P. Vazquez, L. Pizzio, G. Romanelli, J. Autino, C. Caceres, M. Blanco, Appl. Catal. A 2002, 235, 233-240.

[23] I. V. Kozhevnikov, A. Sinnema, R. J. J. Jansen, K. Pamin, H. van Bekkum, Catal. Lett. 1994, 30, 241-252.

[24] F. Marme, G. Coudurier, J. C. Vedrine, Microporous Mesoporous Mater. 1998, 22, 151-163.

[25] W. Kim, M. Kim, J. Kim, G. Seo, Microporous Mesoporous Mater. 2003, 57, 113-120.

[26] A. Bielanski, A. Lubanska, J. Pozniczek, A. Micek-Ilnicka, Appl. Catal. A 2003, 238, 239-250.

[27] L. R. Pizzio, P. G. Vazquez, C. V. Caceres, M. N. Blanco, Appl. Catal. A 2003, 256, 125-139.

[28] J. G. Hernandez-Cortez, T. López, M. E. Manriquez, R. Gómez, J. Navarrete, J. Sol-Gel Sci. Technol. 2003, 26, 213216.

[29] B. Bachiller-Baeza, J. A. Anderson, J. Catal. 2002, 212, 231239.

[30] S. Jiang, Y. Guo, C. Wang, X. Qu, L. Li, J. Colloid Interface Sci. 2007, 308, 208-215.

[31] R. Mukai, T. Sugiyama, H. Tamon, Appl. Catal. A 2003, 256, 99-105.

[32] S. Hodjati, K. Vaezzadeh, C. Petit, V. Pitchon, A. Kiennemann, Top. Catal. 2001, 16-17, 151-155.

[33] P. Madhusudhan Rao, A. Wolfson, S. Kababya, S. Vega, M. V. Landau, J. Catal. 2005, 232, 210-225.

[34] a) E. Papacostantinou, Chem. Soc. Rev. 1989, 18, 1-31; b) D. Sattari, C. L. Hill, J. Am. Chem. Soc. 1993, 115, 4649-4657.

[35] H. Park, W. Choi, J. Phys. Chem. B 2003, 107, 3885-3890.

[36] G. Marcì, E. I. García-López, L. Palmisano, Appl. Catal. A 2012, 421-422, 70-78.

[37] A. Hiskia, A. Mylonas, E. Papaconstantinou, Chem. Soc. Rev. 2001, 30, 62-69.

[38] a) Z. Huang, Y. V. Geletii, D. G. Musaev, C. L. Hill, T. Lian, Ind. Eng. Chem. Res. 2012, 51, 11850-11859; b) J. J. Stracke, R. G. Finke, ACS Catal. 2013, 3, 1209-1219; c) J. L. Gunjakar, T. W. Kim, J. M. Lee, S. Hwang, Sci. Rep. 2013, 3, 2080-2087; d) M. D. Symes, R. J. Cogdell, L. Cronin, Phil. Trans. R. Soc. A 2013, 371, 20110411.

[39] a) K. Mori, K. Furubayashi, S. Okada, H. Yamashita, RSC $A d v$. 2012, 2, 1047-1054; b) B. Keita, T. Liu, L. Nadjo, J. Mater. Chem. 2009, 19, 19-33.

[40] Y. Guo, C. Hu, J. Mol. Catal. A 2007, 262, 136-148; a) Y. Guo, C. Hu, Y. Wang, E. Wang, Y. Zhou, S. Feng, Chem. Mater. 
2000, 12, 3501-3508; b) Y. Guo, Y. Yang, C. Hu, C. Guo, E. Wang, Y. Zhou, S. Feng, J. Mater. Chem. 2002, 12, 3046-3052; c) Y. Guo, C. Hu, S. Jiang, C. Guo, Y. Yang, E. Wang, Appl. Catal. B 2002, 36, 9-17.

[41] Y. Guo, C. Hu, C. Jiang, Y. Yang, S. Jiang, X. Li, E. Wang, J. Catal. 2003, 217, 141-151.

[42] H. Shen, H. Mao, L. Ying, Q. Xi, J. Mol. Catal. A 2007, 276, 73-79.

[43] C. Feng, Y. Li, X. Liu, Chin. J. Chem. 2012, 30, 127-132.

[44] L. Zhao, Y. Chi, Q. Yuan, N. Li, W. Yan, X. Li, J. Colloid Interface Sci. 2013, 390, 70-77.

[45] R. R. Ozer, J. L. Ferry, J. Phys. Chem. B 2002, 106, 4336- 4342.

[46] C. Leal Marchena, R. A. Frenzel, S. Gomez, L. B. Pierella, L. R. Pizzio, Appl. Catal. B 2013, 130-131, 187-196.

[47] I. A. Weinstock, Chem. Rev. 1998, 98, 113-170.

[48] N. M. Dimitrievic, D. Savic, O. I. Micic, A. J. Nozik, J. Phys. Chem. 1984, 88, 4278-4283.

[49] M. Yoon, J. A. Chang, Y. Kim, J. R. Choi, K. Kim, S. J. Lee, J. Phys. Chem. B 2001, 105, 2539-2545.

[50] a) T. Tachikawa, M. Fujitsuka, T. Majima, J. Phys. Chem. C 2007, 111, 5259-5275; b) T. Tachikawa, S. Tojo, M. Fujitsuka, T. Majima, Chem. Eur. J. 2006, 12, 3124-3131.

[51] G. Marcì, E. García-López, M. Bellardita, F. Parisi, C. Colbeau-Justin, S. Sorgues, L. F. Liotta, L. Palmisano' Phys. Chem. Chem. Phys. 2013, 15, 13329-13342.

[52] R. R. Ozer, J. L. Ferry, Environ. Sci. Technol. 2001, 35, 3242 3246.

[53] R. Akid, J. R. Darwent, J. Chem. Soc., Dalton Trans. 1985, 395-399.

[54] R. F. Renneke, M. Pasquali, C. L. Hill, J. Am. Chem. Soc. 1990, 112, 6585-6594.

[55] C. Chen, P. Lei, H. Ji, W. Ma, J. Zhao, H. Hidaka, N. Serpone, Environ. Sci. Technol. 2004, 38, 329-337.

[56] Y. Yang, Q. Wu, Y. Guo, C. Hu, E. Wang, J. Mol. Catal. A 2005, 225, 203-212.

[57] L. Li, Q. Wu, Y. Guo, C. Hu, Microporous Mesoporous Mater. 2005, 87, 1-9.

[58] H. Jin, Q. Wu, W. Pang, J. Hazard. Mater. 2007, 141, 123-127.

[59] X. Yu, Y. Guo, L. Xu, X. Yang, Y. Guo, Colloids Surf. A 2008, $316,110-118$

[60] J. Li, W. Kang, X. Yang, X. Yu, L. Xu, Y. Guo, H. Fang, S. Zhang, Desalination 2010, 255, 107-116.

[61] L. Xu, X. Yang, Y. Guo, F. Ma, Y. Guo, X. Yuan, M. Huo, J. Hazard. Mater. 2010, 178, 1070-1077.

[62] S. Kim, W. Choi, J. Phys. Chem. B 2005, 109, 5143-5149.

[63] F. Ma, T. Shi, J. Gao, L. Chen, W. Guo, Y. Guo, S. Wang, Colloids Surf. A 2012, 401, 116-125.

[64] A. Proust, Chem. Soc. Rev. 2012, 41, 7605-7622.

[65] K. Lv, Y. Xu, J. Phys. Chem. B 2006, 110, 6204-6212.

[66] a) J. A. Rengifo-Herrera, M. N. Blanco, L. R. Pizzio, Appl. Catal. B 2011, 110, 126-132; b) J. A. Rengifo-Herrera, L. R. Pizzio, M. N. Blanco, C. Roussel, C. Pulgarin, Photochem. Photobiol. Sci. 2011, 10, 29-34.

[67] M. Blanco, L. Pizzio, Appl. Catal. A 2011, 405, 69-78.

[68] R. Ngo Biboum, C. P. Nanseu Njiki, G. Zhang, U. Kortz, P. Mialane, A. Dolbecq, I. M. Mbomekalle, L. Nadjo, B. Keita, J. Mater. Chem. 2011, 21, 645-650.

[69] H. Lee, J. Lee, Y. H. Lee, J. Lee, M. Yoon, J. Mater. Chem. 2011, 21, 12829-12835.

[70] H. Shi, T. Zhang, T. An, B. Li, X. Wang, J. Colloid Interface Sci. 2012, 380, 121-127.

[71] D. Wu, P. Huo, Z. Lu, X. Gao, X. Liu, W. Shi, Y. Yan, Appl. Surf. Sci. 2012, 258, 7008-7015.

[72] C. Feng, G. Xu, X. Liu, J. Rare Earths 2013, 31, 41-48.

[73] S. Anandan, S. Ryu, W. Cho, M. Yoon, J. Mol. Catal. A 2003, 195, 201-208.
[74] N. Dubey, S. S. Rayalu, N. K. Labhsetwar, R. R. Naidu, R. V. Chatti, S. Devotta, Appl. Catal. A 2006, 303, 152-157.

[75] R. Chatti, S. S. Rayalu, N. Dubey, N. Labhsetwar, S. Devotta, Sol. Energy Mater. Sol. Cells 2007, 91, 180-190.

[76] A. T. Najafabadi, F. Taghipour, J. Photochem. Photobiol. A: Chem. 2012, 248, 1-7.

[77] A. Navío, M. C. Hidalgo, G. Colón, S. G. Botta, M. Litter, Langmuir 2001, 17, 202-210.

[78] X. Qu, Y. Guo, C. Hu, J. Mol. Catal. A 2007, 262, 128-135.

[79] C. Jiang, Y. Guo, C. Hu, C. Wang, D. Li, Mater. Res. Bull. 2004, 39, 251-257.

[80] S. Farhadi, M. Zaidi, Appl. Catal. A 2009, 354, 119-126.

[81] H. Salavati, N. Tavakkoli, M. Hosseinpoor, Ultrason. Sonochem. 2012, 19, 546-553.

[82] K. Sayama, H. Arakawa, J. Photochem. Photobiol. A: Chem. 1994, 77, 243-247.

[83] T. Murase, H. Irie, K. Hashimoto, J. Phys. Chem. B 2004, 108, 15803-15807.

[84] a) L. Xu, Y. Wang, X. Yang, X. Yu, Y. Guo, J. H. Clark, Green Chem. 2008, 10, 746-755; b) L. Xu, X. Yang, X. Yu, Y. Guo, Maynurkader, Catal. Commun. 2008, 9, 1607-1611; c) L. Xu, W. Li, J. Hu, K. Li, X. Yang, F. Ma, Y. Guo, X. Yu, Y. Guo, J. Mater. Chem. 2009, 19, 8571-8579; d) L. Xu, Y. Wang, X. Yang, J. Hu, W. Li, Y. Guo, Green Chem. 2009, 11, 314-317.

[85] S. Jiang, Y. Guo, C. Wang, X. Qu, L. Li, J. Colloid Interface Sci. 2007, 308, 208-215.

[86] S. Li, X. Yu, G. Zhang, Y. Ma, J. Yao, B. Keita, L. Nadjo, H. Zhao, J. Mater. Chem. 2011, 21, 2282-2287.

[87] X. Xing, R. Liu, X. Yu, G. Zhang, H. Cao, J. Yao, B. Ren, Z. Jiang, H. Zhao, J. Mater. Chem. A 2013, 1, 1488-1494.

[88] H. N. Kim, T. W. Kim, K. H. Choi, I. Y. Kim, Y. R. Kim, S. J. Hwang, Chem. Eur. J. 2011, 17, 9626-9633.

[89] H. Yang, T. Liu, M. Cao, H. Li, S. Gao, R. Cao, Chem. Commun. 2010, 46, 2429-2431.

[90] M. Cao, J. Lin, J. Lu, Y. You, T. Liu, R. Cao, J. Hazard. Mater. 2011, 186, 948-951.

[91] J. Lü, J.-X. Lin, X.-L. Zhao, R. Cao, Chem. Commun. 2012, 48, 669-671.

[92] Y. You, S. Gao, Z. Yang, M. Cao, R. Cao, J. Colloid Interface Sci. 2012, 365, 198-203.

[93] M. Bonchio, M. Carraro, G. Scorrano, A. Bagno, Adv. Synth. Catal. 2004, 346, 648-654.

[94] W. Zhou, M. Cao, S. Su, N. Li, X. Zhao, J. Wang, X. Li, C. Hu, J. Mol. Catal. A 2013, 371, 70-76.

[95] A. Corma, H. García, F. X. Llabrés, I. Xamena, Chem. Rev. 2010, 110, 4606-4655.

[96] H. Y. An, D. R. Xiao, E. B. Wang, Y. G. Li, X. L. Wang, L. $\mathrm{Xu}$, Eur. J. Inorg. Chem. 2005, 854-859.

[97] a) C. Y. Sun, S. X. Liu, D. D. Liang, K. Z. Shao, Y. H. Ren, Z. M. Su, J. Am. Chem. Soc. 2009, 131, 1883-1888; b) N. V. Maksimchuk, M. N. Timofeeva, M. S. Melgunov, A. N. Shmakov, Y. A. Chesalov, D. N. Dybtsev, V. P. Fedin, O. A. Kholdeeva, J. Catal. 2008, 257, 315-323.

[98] J. Guo, J. Yang, Y. Liu, J. Ma, Inorg. Chim. Acta 2013, 400, $51-58$.

[99] B. Liu, J. Yang, G. Yang, J. Ma, Inorg. Chem. 2013, 52, 84-94.

[100] B. Meng, W. You, X. Sun, F. Zhang, M. Liu, Inorg. Chem. Commun. 2011, 14, 35-37.

[101] R. Ngo Biboum, F. Doungmene, B. Keita, P. Oliveira, L. Nadjo, B. Lepoittevin, P. Roger, F. Brisset, P. Mialane, A. Dolbecq, I. M. Mbomekalle, C. Pichon, P. Yin, T. Liu, R. Contant, J. Mater. Chem. 2012, 22, 319-323.

[102] Z. Fu, Y. Zeng, X. Liu, D. Song, S. Liao, J. Dai, Chem. Commun. 2012, 48, 6154-6156.

Received: July 11, 2013

Published Online: October 2, 2013 